\title{
POLÍTICAS PARA O ENSINO SUPERIOR E CAMPOS DISCIPLINARES: PERCEPÇÕES DE DOCENTES DA UNIVERSIDADE DE BRASÍLIA
}

\section{HIGHER EDUCATION POLICIES AND DISCIPLINARY FIELDS: \\ PERCEPTIONS OF FACULTY MEMBERS OF \\ THE UNIVERSIDADE DE BRASÍLIA}

LES POLITIQUES DE L'ENSEIGNEMENT SUPÉRIEUR

ET LES CHAMPS DISCIPLINAIRES : LES PERCEPTIONS DES PROFESSEURS DE L'UNIVERSIDADE DE BRASÍLIA

\author{
POLÍTICAS PARA LA ENSEÑANZA SUPERIOR \\ Y CAMPOS DISCIPLINARES: PERCEPCIONES DE \\ DOCENTES DE LA UNIVERSIDADE DE BRASÍLIA
}

\author{
Jacques Velloso * \\ Patricia Gatto **
}

\begin{abstract}
RESUMO
O estudo discute percep̧̧ôes de docentes da UnB quanto a questōes das politicas para a educação superior do final dos anos 90, boa parte delas ainda relevantes para o projeto da chamada "reforma da universidade" do governo Lula. Os dados foram obtidos mediante uma amostra aleatória de $10 \%$ dos professores da instituição. As análises foram feitas com base na hipótese de que mestres e doutores tenderiam a ter percepçôes diferenciadas quanto às referidas questôes e que a inserção em campos disciplinares distintos também afetaria essas percepçōes. Em algumas questôes, e principalmente no campo das humanidades e ciências sociais, encontraram-se diferenças significativas por nível de titulação, como no caso da isonomia salarial, mais favorecida pelos mestres, ou no caso da dedicação exclusiva, à qual os doutores atribuem maior importância. Entretanto, na maioria das questōes as respostas foram indiferenciadas, sugerindo o predominio de uma subcultura acadêmica na instituição.
\end{abstract}

Palavras-chave: Politicas de ensino superior. Reforma universitária. Universidade de Brasilia. Docentes. Mestres e doutores. Campos disciplinares.

* Doutor em Educação pela Stanford University (EUA, 1975). Professor Titular da Faculdade de Educação da Universidade de Brasília - UnB (j.velloso@globo.com).

** Mestra em Educação pelo Programa de Pós-Graduação em Educação da UnB. Consultora do Instituto Avaliação (pattgatto@hotmail.com). 


\section{INTRODUÇÃO}

Uma questão central deste texto se refere às percepções de docentes da UnB quanto a políticas para a educação superior, considerando o contexto no qual desenvolvem suas atividades. Essa foi uma das questōes que orientou um projeto de investigação iniciado por Aragón, Rocha e Matos (1997), posteriormente retomado em alguns de seus aspectos por outros investigadores e por Gatto (2002), em estudo no qual se baseia o presente artigo. Uma das finalidades daquele projeto foi a de identificar e analisar percepçôes dos docentes da UnB quanto a questôes das políticas para a educação superior da época, propostas ou gestadas no âmbito da reforma do Estado que então se efetuava. O conjunto das questôes sugeria algumas importantes diretrizes para uma reforma da educação superior no País, com especial referência às universidades federais. A maioria daquelas questôes ainda hoje tem pertinência para o debate sobre a reforma da educação superior - freqüentemente chamada de "reforma universitária" -, em curso no ano de 2005.

$\mathrm{Na}$ análise de percepçôes de docentes universitários, dois conceitos são particularmente úteis: o de paradigma e o de cultura disciplinar. O primeiro ganhou espaço nos debates sobre filosofia da ciência, a partir da obra de Kuhn, dos anos 60, embora o próprio autor reconheça certa elasticidade no tratamento original do conceito de paradigma, conforme discute em post scriptum da edição dos anos $70 .{ }^{1}$ A essência do conceito, se é possível reduzi-lo a seus termos básicos, diz respeito a crenças compartilhadas quanto aos modos de produzir ciência, numa área do conhecimento. Como indica Velho (1998), a noção de paradigma, sempre referida a uma área do conhecimento - ou conjunto de áreas -, designa o grau de consenso em torno de teorias, de questóes metodológicas e técnicas, de critérios de julgamento da produção científica e da relevância dos problemas para a ciência. Ao tratar de graus de consenso, ou de compartilhamento de crenças por parte dos membros de uma dada comunidade científica, Kuhn sugere um gradiente de desenvolvimento de paradigmas, considerando que as ciências físicas (e, por extensão, as ciências naturais) têm paradigmas mais maduros, isto é, que desfrutam de elevado grau de consenso entre os pesquisadores, enquanto as ciências humanas e sociais se situariam numa fase pré-paradigmática, ou seja, com baixo grau de consenso.

Se a universidade é um locus privilegiado para a produção do conhecimento - como ocorre com a universidade pública brasileira -, então diferenças no grau de compartilhamento de crenças quanto aos modos de fazer ciência podem influir em percepções quanto a questôes que digam respeito à instituição universitária. Disso decorre a utilidade do conceito de paradigma no estudo de percepçóes de professores quanto a políticas que se refiram à universidade.

A noção de cultura disciplinar tem serventia análoga. As origens da noção podem ser identificadas nos estudos de Clark (1983) sobre a profissão acadêmica. Na esteira dessas origens, Becher (1992) realizou estudo analisando em que medida os docentes universitários se consideravam como membros de uma única profissão, ou se viam como integrantes de diferentes grupos da profissão acadêmica. Na raiz dessas percepçôes, estariam características epistemológicas e sociais de diferentes disciplinas, que também foram investigadas, assim como o foram as representaçōes da cultura de cada uma delas. $\mathrm{O}$ estudo conduziu à classificação das disciplinas em dois grandes grupos, de certa forma semelhantes 
aos anteriormente mencionados, e à subdivisão de cada um desses em dois campos disciplinares.

Um desses campos disciplinares, o das Ciências Duras-Puras, caracteriza-se por problemas de pesquisa que podem ser subdivididos em pequenos segmentos, com uma estrutura de investigação cumulativa. Essas disciplinas desenvolvem-se baseadas na universalidade e no quantificável, tendo como resultado de pesquisa satisfatório a descoberta de algo novo ou, pelo menos, o esclarecimento de algo ainda não explicado. Já nas Ciências Duras-Aplicadas, a estrutura do conhecimento não é necessariamente cumulativa, embora possa depender de tal acumulação. Não são sempre baseadas na quantificação, pois podem usar também elementos qualitativos. Os trabalhos em geral têm em vista alguma finalidade prática, preocupando-se menos em dominar efetivamente o mundo físico e mais em obter produtos e técnicas como resultados de pesquisa.

As Ciências Brandas-Puras, que freqüentemente fazem incursões em terrenos já explorados, têm seus temas de pesquisa muitas vezes repetidos, embora vistos sob perspectivas diferentes. Desenvolvem-se mediante estudo de problemas multivariados, que não se subdividem e que têm como ponto de partida instâncias particulares, em comparação com características gerais. Os produtos das pesquisas resultam, na maioria das vezes, na interpretação e na análise de fatos já conhecidos, priorizando-se as complexidades e o qualitativo. Já as Ciências Brandas-Aplicadas dependem do conhecimento brando-puro, utilizado para entender as complexidades humanas. A efetividade dos resultados de pesquisa dessas ciências, reformulados com freqüência, geralmente se relaciona à sua funcionalidade e utilidade.

As características dos campos disciplinares identificadas pelo autor, quanto à estrutura e modos de produção do conhecimento, configurariam culturas disciplinares diversas, associadas a estilos de atuação na profissão acadêmica igualmente distintos. Tal diversidade, por seu turno, naturalmente poderia conduzir a percepções diferenciadas quanto a questôes que dizem respeito à universidade.

A titulação também pode influir nas percepçōes dos docentes quanto a questōes referentes à universidade. A formação pós-graduada mais alongada dos doutores, e mais curta no caso dos mestres, envolve processos com diferentes graus de intensidade de socialização na respectiva cultura disciplinar. Nessa ótica, doutores, comparativamente a mestres, estariam mais solidamente inseridos na respectiva cultura disciplinar, o que teria como consequiência diferenças nas percepções sobre tudo aquilo que tal cultura viesse a influenciar. Numa outra perspectiva, que não exclui a anterior, antes a complementa, a titulação estaria associada à autoridade acadêmica. Na concepção de Bourdieu (1994), essa autoridade - ou poder acadêmico - pode ser definida em termos de prestígio e reconhecimento, constituindo o pacto mediante o qual os interlocutores do processo de diálogo, reflexão, troca de idéias e experiências - como os docentes e estudantes respeitam as regras básicas desses processos. Nessa medida, graus mais elevados de legitimidade do poder acadêmico poderiam corresponder a uma maior convergência de percepções, ao longo da hierarquia de títulos, no que diz respeito a muitos aspectos da vida universitária, do mesmo modo que, onde a autoridade acadêmica tivesse menor aceitação, essas percepções tenderiam a ser menos convergentes. 
O presente texto está dividido em quatro seçôes, além desta Introdução. Na seção seguinte, apresentam-se os objetivos do estudo e, na terceira, abordam-se questôes conceituais e metodológicas. Na quarta seção, discutem-se os dados obtidos e, na última, resumem-se os principais resultados.

\section{OBJETIVOS}

O estudo buscou analisar percepções de professores da UnB quanto a questōes de políticas públicas para a educação superior, as quais integravam um projeto de investigação de Aragón, Rocha e Matos (1997), mas não haviam sido analisadas pelos seus autores. A grande maioria dessas questôes ainda hoje tem interesse para as discussóes que se travam sobre a reforma da educação superior, no corrente ano de $2005 ;^{2}$ em seu conjunto abrangem nove variáveis, com especial referência à universidade federal, agrupadas em quatro blocos: (i) organização da educação superior, envolvendo: universidades federais e relação com o Estado; vocação e funçōes da universidade; novos tipos de organizações na educação superior; (ii) gestão da universidade, referida a administradores profissionais; (iii) financiamento da universidade federal, abrangendo: cobrança de taxas na especialização; autonomia e geração de recursos próprios; (iv) carreira docente na universidade federal, compreendendo: isonomia salarial; dedicação exclusiva; estabilidade funcional.

Uma das hipóteses do estudo foi a de que mestres e doutores tenderiam a ter percepções distintas quanto à reforma da educação superior, em função de diferenças no ethos acadêmico. Assim, procurou-se detectar e analisar possíveis diferenças nas percepçōes de docentes com distinta titulação acadêmica, no que se refere a questōes da mencionada reforma da educação superior. ${ }^{3}$ Outra hipótese foi a de que campos disciplinares distintos ensejam culturas acadêmicas diversas, que também podem influir sobre as referidas percepçôes. Em vista disso, o estudo buscou controlar essas possíveis influências, comparando as opiniōes de mestres e doutores dentro de cada campo.

\section{QUESTÕES CONCEITUAIS E METODOLÓGICAS}

Nessa seção, discutem-se as definições das variáveis no plano conceitual e operacional, os demais procedimentos metodológicos empregados, e abordam-se características da amostra utilizada.

\section{Questões do estudo e as variáveis no plano conceitual e empírico}

No referido projeto de investigação original, o questionário aplicado a docentes da UnB continha nove enunciados sintéticos sobre a reforma da educação superior. A maioria resumia aspectos de políticas propostas ou gestadas pelo governo no âmbito da reforma do Estado; outros resumiam contrapropostas, em discussão no meio acadêmico e no meio sindical universitário. 
No presente estudo, esses enunciados estão classificados em quatro blocos. O primeiro diz respeito a questōes da organização da educação superior, no sentido lato da expressão. $\mathrm{O}$ primeiro item do bloco refere-se a uma mudança no ordenamento jurídico que incide sobre as universidades federais, contida na afirmativa apresentada no questionário: as universidades públicas federais devem deixar de ser estatais. Conectando-se a esse enunciado, um outro item se refere à criação de novos tipos de organizaçôes para reestruturar a educação superior. Embora o enunciado hoje pareça algo impreciso, na época em que o questionário foi aplicado o sentido era bastante claro, pois a discussão sobre o assunto se concentrava na criação de Organizações Sociais - OS, que atuariam mediante contratos de gestão com o governo, como vinha insistindo Bresser-Pereira (1995), então Ministro da Administração Federal e Reforma do Estado, apesar da impropriedade da aplicação desses contratos às universidades, como há muito advertiam Neave e Van Vught (1991) no contexto europeu. ${ }^{4} \mathrm{O}$ enunciado correspondente a essa outra variável, à qual estava subjacente o debate sobre as OS e os contratos de gestão, é: o Estado deve criar novos tipos de organizaçôes para reestruturar o ensino superior. Outra variável do bloco tem implicações para a organização das universidades, embora não se refira diretamente ao tema. A afirmativa oferecida aos professores foi: cada universidade deve descobrir sua melhor vocação, especializando-se na pesquisa, ensino ou extensão, conforme o caso. Nos termos do debate de então, tratava-se de uma proposta que para alguns rompia com o modelo de universidade estabelecido pela Constituição Federal de 1988, de indissociabilidade de ensino, pesquisa e extensão, enquanto para outros consistia no melhor aproveitamento dos recursos acadêmicos de cada instituição.

No bloco referente à gestão, a única variável se baseia em tema da agenda do governo da segunda metade dos anos 90, que no âmbito da reforma do Estado retomava propostas de modernização de 30 anos antes. Um dos importantes protagonistas na difusão das propostas modernizantes da educação superior no Estado autoritário pós-1964 foi Rudolph Atcon, contratado como consultor da Secretaria (então Diretoria) do Ensino Superior do MEC, e que desembarcou novamente no Brasil após ter prestado serviços ao ministério na década anterior (CUNHA, 1988). Segundo uma dessas propostas, o reitor de uma instituição contrataria um profissional não pertencente ao quadro de professores para, nas palavras de Cunha (cit., p. 324), "gerir 'sua' universidade, como se fosse uma fábrica [...], buscando produzir mercadorias e serviços que, vendidos, resultariam numa receita compensadora diante dos custos". Tal proposta da década de 60, retomada pela reforma do Estado dos anos 90, encontrou a seguinte expressão no questionário: as universidades devem ser gerenciadas por administradores profissionais contratados, não pertencentes ao quadro de docentes.

Nos anos 90, a proposta de administradores profissionais parece ter entrado novamente no País a partir das experiências que se seguiram à reforma educacional de 1988 na Grã-Bretanha, na esteira do Estado mínimo inaugurado pelo governo Tatcher vários anos antes. $\mathrm{O}$ aumento de gestores na universidade inglesa ao longo da década passada não foi um fenômeno fortuito nem isolado, inserindo-se num conjunto de políticas orientadas para a eficiência e desempenho da universidade, em detrimento da igualdade de oportunidades e de sua missão histórica e cultural, e para uma concepção utilitarista, que volta a face da instituição para a economia, em lugar do exercício de seu papel de reflexão crítica na sociedade (COWEN, 2004). 
O terceiro bloco de itens trata de questóes do financiamento das universidades federais. Um desses itens, refletindo práticas que já vinham sendo adotadas no País - principalmente à vista da penúria financeira a que estavam (e ainda hoje estão) sendo submetidas as federais -, mas que não haviam sido oficializadas, tratava da cobrança de taxas na pósgraduação lato sensu. Para alguns, a prática contrariaria a gratuidade da educação superior pública, consagrada na Constituição; para outros, seria uma tolerável ou mesmo indispensável exceção à regra, que seria mantida em sua essência com a gratuidade na graduação e na pós-graduação stricto sensu, na qual se concentra a grande maioria da matrícula. $\mathrm{O}$ questionário apresentou a seguinte afirmativa aos informantes: devem ser cobradas taxas nos cursos de pós-graduação lato sensu (especialização) nas universidades federais.

$\mathrm{O}$ outro item do bloco se refere a relações entre recursos e autonomia e assim se expressou no questionário: a autonomia das universidades federais deve incluir a obrigatoriedade de estas gerarem pelo menos uma parte de seus recursos financeiros. A gestão financeira das universidades federais, como se sabe, sempre padeceu de rígidos e inadequados controles burocráticos por parte do Estado (AMARAL, 2003; VELLOSO, 2000), mas entre essas instituiçôes desde há tempos existe marcante distância na capacidade de produzir receitas próprias, na qual tem se destacado a UnB. Mais ou menos em fins da década de 90, por exemplo, os recursos próprios gerados pelas federais correspondiam a somente $5 \%$ de seus orçamentos (SCHWARTZMAN, 1998), embora na UnB abrangessem fatia cerca de cinco vezes maior (VELLOSO; MARQUES, 2005).

$\mathrm{O}$ quarto bloco compreende três aspectos da carreira docente. $\mathrm{O}$ primeiro deles se refere à isonomia salarial para docentes, que há muito vem sendo amplamente debatida, continua a sê-lo até hoje, mas que na prática foi superada (pelo menos em parte) pela Gratificação de Estímulo à Docência - GED, adotada em 1998 no governo Fernando Henrique Cardoso e, no segundo semestre de 2004, provisoriamente congelada no governo Luís Inácio Lula da Silva, no bojo da discussão sobre a reforma da educação superior e de movimentos grevistas de professores. Pediu-se aos docentes sua opinião sobre a seguinte afirmativa: a isonomia salarial para os professores das universidades federais deve ser mantida. $\mathrm{O}$ segundo item é relativo à dedicação exclusiva, mecanismo implementado na esteira da reforma da educação superior de 1968, que consistiu em forte estímulo ao desenvolvimento da pesquisa nas universidades, notadamente na pós-graduação, e que alterou radicalmente a natureza do corpo docente, no sentido de sua profissionalização. $\mathrm{O}$ respectivo enunciado constante do questionário foi: a dedicação exclusiva deve ser mantida nas universidades federais para o corpo docente. $\mathrm{O}$ item final do bloco foi originalmente formulado à vista do debate sobre a estabilidade funcional do servidor público, que na época se rompia com a reforma do Estado então em curso: a quebra da estabilidade funcional do servidor não deveria ter incluido o corpo docente das universidades federais (grifo no original). 


\section{Formato de apresentação dos resultados e agrupamento de categorias}

Perguntou-se aos professores sua opinião sobre cada um dos referidos nove enunciados, oferecendo-lhes quatro alternativas de resposta: discordo totalmente, discordo parcialmente, concordo parcialmente e concordo totalmente. $\mathrm{O}$ agrupamento inicial das alternativas considerou que, conforme tabelas de contingência, as probabilidades de significância estatística de eventuais diferenças existentes dependem da combinação da quantidade de categorias em cada variável (graus de liberdade) com o tamanho da amostra (número de casos). Diante do tamanho da amostra, com cerca de 100 casos, num primeiro momento da tabulação dos dados as quatro categorias originais foram agrupadas em duas: a primeira, discordo, compreendendo as discordâncias plena e parcial, e a segunda, de modo análogo, na categoria concordo. Esse modo de agrupamento, que é habitualmente empregado em variáveis nominais como as do presente estudo, está apresentado nas colunas sob o título "classificação padrão", nas tabelas 1 a 4 da seção seguinte.

As opinióes dos professores para cada um dos enunciados, agrupadas nessas duas categorias, foram tabuladas por nível de titulação. Em seguida, ainda nesse primeiro momento da tabulação, o nível de titulação foi controlado pelo campo disciplinar, isto é, os resultados foram tabulados por nível de titulação dentro de cada campo disciplinar.

$\mathrm{O}$ modo de agrupamento das respostas que se utilizou no primeiro momento da tabulação é intuitivamente lógico: o marco divisório, ou ponto de corte, situa-se entre os que manifestaram algum grau de discordância e os que indicaram algum grau de concordância. Mais importante ainda é que esse ponto de corte em princípio evita que se compare um grupo compreendendo uma grande quantidade de sujeitos com outro, de tamanho diminuto; ${ }^{5}$ tal comparação estaria longe de indicar tendências na população estudada. No entanto, em investigações que usam variáveis nominais ou categóricas, uma questão sempre presente é: qual é o ponto de corte adequado? Por outras palavras, se existem diferenças, onde de fato elas se situam? Ou, ainda, onde elas são mais nítidas? Cabe ao pesquisador explorar outros pontos de corte, além do que é habitualmente utilizado, sobretudo quando em algumas variáveis há respostas concentradas num dos extremos da escala.

O enunciado sobre dedicação exclusiva é bem ilustrativo dessa concentração. Nesse quesito, $55 \%$ dos docentes escolheram a opção concordo totalmente. Assim, num segundo momento da preparação dos dados para a tabulação, escolheu-se um ponto de corte adicional para a aglutinação das categorias, em acréscimo à "classificação padrão" antes aludida: os que concordavam plenamente foram separados dos demais professores, ou seja, daqueles que assinalaram uma das três outras alternativas de resposta.

Nesse segundo momento da preparação dos dados para tabulação, o procedimento foi repetido com as demais variáveis do estudo. Constatou-se que, em sete dessas nove variáveis, a maior freqüência de respostas situava-se num dos extremos da escala de concordância. Adotaram-se então os seguintes critérios para os pontos de corte adicionais. Quando a maior freqüência de respostas situava-se no extremo superior da escala (opção concordo totalmente), o ponto de corte adicional para a agregação das categorias foi idêntico ao do item sobre dedicação exclusiva. Os resultados para esse tipo de agrupamento estão apresentados nas duas últimas colunas das tabelas do estudo, sob o título "contraste 
concordância”. Quando a maior frequiência de respostas localizava-se no extremo inferior da escala (categoria discordo totalmente), o ponto de corte adicional situou-se entre os assinalaram esta opção e os demais docentes. Os dados para esse agrupamento são apresentados nas duas colunas intermediárias das tabelas, sob o título "contraste discordância". Duas variáveis são exceções a esses dois critérios. Nelas, as respostas estavam concentradas na metade superior da escala, mas a alternativa de total concordância era a segunda maior freqüência; esse foi o caso da variável sobre a vocação das universidades e daquela sobre a cobrança de taxas nos cursos de especialização. Nesses dois casos, o agrupamento adicional obedeceu ao ponto de corte adotado para a variável referente à dedicação exclusiva. Nos pontos de corte adicionais para todas as nove variáveis, cada extremo abrangeu, no mínimo, em torno de $25 \%$ das respostas.

\section{Questões do estudo e amostra}

$\mathrm{Na}$ pesquisa original, o questionário foi aplicado a uma amostra aleatória simples de $10 \%$ do universo de docentes da UnB, em 1998. Os dados então obtidos foram atualizados no ano seguinte por Gatto (2002), a partir de informações constantes do cadastro dos professores da universidade; além disso, efetuaram-se alguns recortes julgados apropriados.

Um desses recortes diz respeito à titulação dos docentes, e outro, às áreas do conhecimento estudadas. Tomando em conta que, na época da aplicação dos questionários, já havia, na UnB, um número relativamente pequeno de docentes com graduação e especialização, estes foram suprimidos da amostra que se utilizou no presente estudo ${ }^{6}$ Considerou-se ainda que uma tabulação de dados com os quatro campos disciplinares originalmente propostos por Becher (1992), à vista do tamanho da amostra, da ordem de 100 casos, poderia gerar considerável dispersão nos resultados. Assim, os quatro campos originais do autor foram agregados em dois: Ciências Duras e Ciências Brandas.

Efetuados os recortes discutidos, a amostra utilizada foi integrada por 107 casos, dos quais $35 \%$ dos docentes com mestrado e $65 \%$ com doutorado. No campo das Ciências Duras, os doutores têm amplo predomínio, com $70 \%$; no outro campo, eles correspondem a 56\%. Foi possível comparar algumas características da amostra original, antes dos recortes acima descritos, com as do universo de docentes; nas comparaçôes quanto à titulação, por exemplo, o erro foi de apenas três pontos percentuais.

Todas as possíveis relações apresentadas nas tabelas da seção seguinte foram submetidas ao teste do Qui-quadrado. Em cada tabela, indicam-se os níveis de significância estatística das diferenças observadas. Quando a diferença é significativa numa das relações da "classificação padrão", o símbolo $\left(^{*}\right)$ corresponde ao nível de $10 \%$, e o símbolo (**), ao nível de $5 \%$. Nos outros dois formatos de apresentação de resultados, [xx] indica o nível de 5\% no "contraste discordância", e [zz], no "contraste concordância". Todas as diferenças estatisticamente significativas estão em negrito, a fim de facilitar sua identificação. 


\section{MESTRES E DOUTORES, A REFORMA E OS CAMPOS DISCIPLINARES}

Nesta seção, discutem-se os dados obtidos, iniciando-se com uma descrição das tendências observadas com base na classificação padrão referida na seção anterior. Em seguida, analisam-se os resultados para cada variável, tratando-se primeiro das percepçõos de mestres e doutores no conjunto da amostra e, logo depois, dos resultados controlados por campo disciplinar, isto é, de possíveis diferenças de opinião por titulação no interior de cada um dos dois campos considerados no estudo.

\section{Principais tendências}

No bloco dos itens referentes à organização da educação superior, o conjunto dos docentes da UnB foi francamente desfavorável a uma mudança nas relações das federais com o Estado, conforme mostra a tabela 1 . Cerca de $70 \%$ dos professores discordaram da proposta de que essas universidades deixassem de ser estatais. Nas respostas aos outros dois itens, entretanto, predominou a concordância com as políticas que se desenhavam ao tempo da chamada reforma do Estado. A maioria dos docentes da UnB (60\%) concordou com a idéia de que as universidades deveriam buscar sua vocação, especializando-se no ensino, pesquisa ou a extensão; proporção semelhante também foi a favor da proposição de que o Estado deveria criar novas organizaçōes para reestruturar a educação superior. $\mathrm{O}$ acolhimento deste último enunciado implica, no que se refere à educação superior, aceitação do projeto de governo das Organizaçóes Sociais - OS, elemento que na época dominava o conteúdo da proposição e que veio a materializar-se em lei, fornecendo base legal à noção de "público não-estatal". Note-se, entretanto, que a maioria dos docentes foi contrária ao primeiro item do bloco, indicando que as universidades federais deveriam permanecer estatais; lidas em seu conjunto, aquela aceitação das OS para a educação superior e esta negação de mudança no caráter estatal das federais sugerem que, para os docentes da UnB, o novo formato de organizaçôes não se aplicava ao segmento federal. 
Tabela I - Percepções de docentes da UnB sobre a reforma, por titulação e campo discplinar: organização da educação superior (\%)

\begin{tabular}{|c|c|c|c|c|c|c|c|c|c|}
\hline \multirow{2}{*}{$\frac{8}{2}$} & \multirow[b]{2}{*}{ Item } & \multirow[b]{2}{*}{ Campo } & \multirow{2}{*}{$\begin{array}{l}\text { Titula- } \\
\text { ção }\end{array}$} & \multicolumn{2}{|c|}{$\begin{array}{c}\text { Classificação } \\
\text { padrão }\end{array}$} & \multicolumn{2}{|c|}{$\begin{array}{l}\text { Contraste } \\
\text { discorcância }\end{array}$} & \multicolumn{2}{|c|}{$\begin{array}{c}\text { Contraste } \\
\text { concordância }\end{array}$} \\
\hline & & & & Discordo & Concordo & $\begin{array}{l}\text { Discordo } \\
\text { totalmente }\end{array}$ & $\begin{array}{l}\text { Outras } \\
\text { opções }\end{array}$ & $\begin{array}{l}\text { Outras } \\
\text { opções }\end{array}$ & $\begin{array}{l}\text { Concordo } \\
\text { totalmente }\end{array}$ \\
\hline \multirow{27}{*}{ 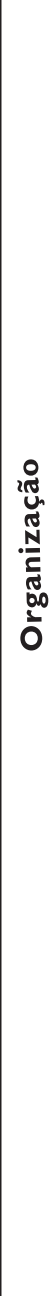 } & \multirow{9}{*}{$\begin{array}{l}\text { Universidades } \\
\text { federais } \\
\text { devem } \\
\text { deixar de } \\
\text { ser estatais }\end{array}$} & \multirow{3}{*}{$\begin{array}{c}\text { Todos } \\
(*)\end{array}$} & Mestrado & 60,5 & 39,5 & 47,4 & 52,6 & - & - \\
\hline & & & Doutorado & 75 & 25 & 55,9 & 44,1 & - & - \\
\hline & & & Total & 69,8 & 30,2 & 52,8 & 47,2 & - & - \\
\hline & & \multirow{3}{*}{$\begin{array}{c}\text { C. } \\
\text { Duras }\end{array}$} & Mestrado & 73,7 & 26,3 & 57,9 & 42,1 & - & - \\
\hline & & & Doutorado & 75 & 25 & 54,5 & 45,5 & - & - \\
\hline & & & Total & 74,6 & 25,4 & 55,6 & 44,4 & - & - \\
\hline & & \multirow{3}{*}{$\begin{array}{c}\text { C. } \\
\text { Brandas } \\
(*)\end{array}$} & Mestrado & 47,4 & 52,6 & 36,8 & 63,2 & - & - \\
\hline & & & Doutorado & 75 & 25 & 58,3 & 41,7 & - & - \\
\hline & & & Total & 62,8 & 37,2 & 48,8 & 51,2 & - & - \\
\hline & \multirow{9}{*}{$\begin{array}{c}\text { Cada } \\
\text { universidade } \\
\text { com sua } \\
\text { vocação: } \\
\text { pesquisa, } \\
\text { ensino ou } \\
\text { extensão }\end{array}$} & \multirow{3}{*}{$\begin{array}{c}\text { Todos } \\
\{\mathrm{zz}\}\end{array}$} & Mestrado & 42,1 & 57,9 & - & - & 89,5 & 10,5 \\
\hline & & & Doutorado & 38,2 & 61,8 & - & - & 67,6 & 32,4 \\
\hline & & & Total & 39,6 & 60,4 & - & - & 75,5 & 24,5 \\
\hline & & \multirow{3}{*}{ C. Duras } & Mestrado & 31,6 & 68,4 & - & - & 89,5 & 10,5 \\
\hline & & & Doutorado & 37,8 & 62,2 & - & - & 71,1 & 28,9 \\
\hline & & & Total & 35,9 & 64,1 & - & - & 76,6 & 23,4 \\
\hline & & \multirow{3}{*}{$\begin{array}{c}\text { C. } \\
\text { Brandas } \\
\{\mathrm{zz}\}\end{array}$} & Mestrado & 52,6 & 47,4 & - & - & 89,5 & 10,5 \\
\hline & & & Doutorado & 39,1 & 60,9 & - & - & 60,9 & 39,1 \\
\hline & & & Total & 45,2 & 54,8 & - & - & 73,8 & 26,2 \\
\hline & \multirow{9}{*}{$\begin{array}{c}\text { Estado deve } \\
\text { criar novas } \\
\text { organizações } \\
\text { para } \\
\text { reestruturar } \\
\text { a educação } \\
\text { superior }\end{array}$} & \multirow{3}{*}{ Todos } & Mestrado & 34,2 & 65,8 & - & - & 73,7 & 26,3 \\
\hline & & & Doutorado & 41,5 & 58,5 & - & - & 66,2 & 33,8 \\
\hline & & & Total & 38,8 & 61,2 & - & - & 68,9 & 31,1 \\
\hline & & \multirow{3}{*}{ C. Duras } & Mestrado & 31,6 & 68,4 & - & - & 73,7 & 26,3 \\
\hline & & & Doutorado & 44,2 & 55,8 & - & - & 67,4 & 32,6 \\
\hline & & & Total & 40,3 & 59,7 & - & - & 69,4 & 30,6 \\
\hline & & \multirow{3}{*}{$\begin{array}{c}\text { C. } \\
\text { Brandas }\end{array}$} & Mestrado & 36,8 & 63,2 & - & - & 73,7 & 26,3 \\
\hline & & & Doutorado & 36,4 & 63,6 & - & - & 63,6 & 36,4 \\
\hline & & & Total & 36,6 & 63,4 & - & - & 68,3 & 31,7 \\
\hline
\end{tabular}

$\left(^{*}\right)$ Diferenças estatisticamente significativas ao nível de $10 \%$ - classificação padrão

\{zz\} Diferenças estatisticamente significativas ao nível de 5\% - contraste concordância (outras opçôes/concordo totalmente) 
Tabela 2 - Percepções de docentes da UnB sobre a reforma, por titulação e campo discplinar: gestão da educação superior (\%)

\begin{tabular}{|c|c|c|c|c|c|c|c|c|c|}
\hline \multirow{2}{*}{$\begin{array}{l}0 \\
\frac{2}{3} \\
\frac{1}{0}\end{array}$} & \multirow{2}{*}{ Item } & \multirow{2}{*}{ Campo } & \multirow{2}{*}{$\begin{array}{l}\text { Titula- } \\
\text { ção }\end{array}$} & \multicolumn{2}{|c|}{$\begin{array}{c}\text { Classificação } \\
\text { padrão }\end{array}$} & \multicolumn{2}{|c|}{$\begin{array}{l}\text { Contraste } \\
\text { discordância }\end{array}$} & \multicolumn{2}{|c|}{$\begin{array}{l}\text { Contraste } \\
\text { concordância }\end{array}$} \\
\hline & & & & Discordo & Concordo & $\begin{array}{l}\text { Discordo } \\
\text { totalmente }\end{array}$ & $\begin{array}{l}\text { Outras } \\
\text { opções }\end{array}$ & $\begin{array}{l}\text { Outras } \\
\text { opções }\end{array}$ & $\begin{array}{l}\text { Concordo } \\
\text { totalmente }\end{array}$ \\
\hline \multirow{9}{*}{ 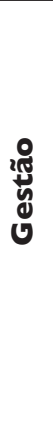 } & \multirow{9}{*}{$\begin{array}{c}\text { Universidades } \\
\text { devem ser } \\
\text { geridas por } \\
\text { administradores } \\
\text { profissionais, } \\
\text { não docentes }\end{array}$} & \multirow{3}{*}{$\begin{array}{c}\text { Todos } \\
{\left[{ }^{\mathrm{xx}}\right]}\end{array}$} & Mestrado & 63,2 & 36,8 & 47,4 & 52,6 & - & - \\
\hline & & & Doutorado & 51,5 & 48,5 & 27,9 & 72,1 & - & - \\
\hline & & & Total & 55,7 & 44,3 & 34,9 & 65,1 & - & - \\
\hline & & \multirow{3}{*}{$\begin{array}{c}\text { C. } \\
\text { Duras }\end{array}$} & Mestrado & 63,2 & 36,8 & 42,1 & 57,9 & - & - \\
\hline & & & Doutorado & 48,9 & 51,1 & 24,4 & 75,6 & - & - \\
\hline & & & Total & 53,1 & 46,9 & 29,7 & 70,3 & - & - \\
\hline & & \multirow{3}{*}{$\begin{array}{c}\text { C. } \\
\text { Brandas }\end{array}$} & Mestrado & 63,2 & 36,8 & 52,6 & 47,4 & - & - \\
\hline & & & Doutorado & 56,5 & 43,5 & 34,8 & 65,2 & - & - \\
\hline & & & Total & 59,5 & 40,5 & 42,9 & 57,1 & - & - \\
\hline
\end{tabular}

[xx] Diferenças estatisticamente significativas ao nível de 5\% - contraste discordância (discordo totalmente/ outras opções)

Embora uma boa maioria dos professores da UnB estivesse convicta de que sua instituição deveria continuar a ser estatal, o corpo docente encontrava-se praticamente cindido quanto à proposição de uma nova forma de gestão das universidades, conforme mostra a tabela 2. Uma escassa maioria de $56 \%$ discordou da idéia de que as universidades - em geral, federais ou não - deveriam ser geridas por administradores profissionais contratados, não pertencentes ao quadro da instituição. Aliás, se as práticas de contratação de gestores nas universidades da Grã-Bretanha, inseridas num conjunto de políticas deletérias para a universidade (COWEN, 2004), tivessem difusão mais ampla que a dos círculos de especialistas aos quais costumam estar restritas, é possível que a escassa maioria contrária tivesse se transformado numa ampla maioria.

No bloco sobre o financiamento das federais, apresentado na tabela 3, uma ampla maioria apoiou os dois enunciados apresentados. Em torno de $80 \%$ dos docentes manifestaram algum grau de concordância com a manutenção da prática de cobrança de taxas na pós-graduação lato sensu das federais - aliás indispensável para a sobrevivência financeira das instituiçôes - e também com a noção de que a autonomia das federais deve envolver a geração de recursos próprios. Assinale-se que, neste último aspecto, a UnB tem a particularidade de que seus recursos próprios representam importante fatia de seu orçamento, como já indicado anteriormente. As despesas feitas pela UnB com esses recursos, geralmente numa grande variedade de itens, exclusive pessoal - os chamados gastos em 
Tabela 3 - Percepções de docentes da UnB sobre a reforma, por titulação e campo disciplinar: financiamento das universidades federais (\%)

\begin{tabular}{|c|c|c|c|c|c|c|c|c|c|}
\hline \multirow{2}{*}{$\frac{8}{3}$} & \multirow{2}{*}{ Item } & \multirow{2}{*}{ Campo } & \multirow{2}{*}{$\begin{array}{l}\text { Titula- } \\
\text { ção }\end{array}$} & \multicolumn{2}{|c|}{$\begin{array}{c}\text { Classificação } \\
\text { padrão }\end{array}$} & \multicolumn{2}{|c|}{$\begin{array}{l}\text { Contraste } \\
\text { discordância }\end{array}$} & \multicolumn{2}{|c|}{$\begin{array}{l}\text { Contraste } \\
\text { concordância }\end{array}$} \\
\hline & & & & Discordo & Concordo & $\begin{array}{l}\text { Discordo } \\
\text { totalmente }\end{array}$ & $\begin{array}{l}\text { Outras } \\
\text { opções }\end{array}$ & $\begin{array}{l}\text { Outras } \\
\text { opções }\end{array}$ & $\begin{array}{l}\text { Concordo } \\
\text { totalmente }\end{array}$ \\
\hline \multirow{18}{*}{ 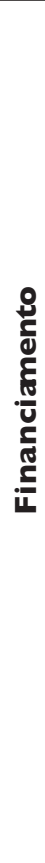 } & \multirow{9}{*}{$\begin{array}{c}\text { Universidades } \\
\text { federais } \\
\text { devem } \\
\text { cobrar taxas } \\
\text { nos cursos } \\
\text { de } \\
\text { especialização }\end{array}$} & \multirow{3}{*}{ Todos } & Mestrado & 15,8 & 84,2 & - & - & 71,1 & 28,9 \\
\hline & & & Doutorado & 24,6 & 75,4 & - & - & 71,0 & 29,0 \\
\hline & & & Total & 21,5 & 78,5 & - & - & 71,0 & 29,0 \\
\hline & & \multirow{3}{*}{$\begin{array}{c}\text { C. } \\
\text { Duras }\end{array}$} & Mestrado & 10,5 & 89,5 & - & - & 73,7 & 26,3 \\
\hline & & & Doutorado & 22,2 & 77,8 & - & - & 75,6 & 24,4 \\
\hline & & & Total & 18,8 & 81,3 & - & - & 75,0 & 25,0 \\
\hline & & \multirow{3}{*}{$\begin{array}{c}\text { C. } \\
\text { Brandas }\end{array}$} & Mestrado & 21,1 & 78,9 & - & - & 68,4 & 31,6 \\
\hline & & & Doutorado & 29,2 & 70,8 & - & - & 62,5 & 37,5 \\
\hline & & & Total & 25,6 & 74,4 & - & - & 65,1 & 34,9 \\
\hline & \multirow{9}{*}{$\begin{array}{l}\text { Autonomia } \\
\text { das } \\
\text { universidades } \\
\text { federais deve } \\
\text { incluir } \\
\text { geração de } \\
\text { recursos } \\
\text { próprios }\end{array}$} & \multirow{3}{*}{ Todos } & Mestrado & 15,8 & 84,2 & - & - & 57,9 & 42,1 \\
\hline & & & Doutorado & 15,9 & 84,1 & - & - & 50,7 & 49,3 \\
\hline & & & Total & 15,9 & 84,1 & - & - & 53,3 & 46,7 \\
\hline & & \multirow{3}{*}{$\begin{array}{c}\text { C. } \\
\text { Duras }\end{array}$} & Mestrado & 5,3 & 94,7 & - & - & 52,6 & 47,4 \\
\hline & & & Doutorado & 17,8 & 82,2 & - & - & 46,7 & 53,3 \\
\hline & & & Total & 14,1 & 85,9 & - & - & 48,4 & 51,6 \\
\hline & & \multirow{3}{*}{$\begin{array}{c}\text { C. } \\
\text { Brandas }\end{array}$} & Mestrado & 26,3 & 73,7 & - & - & 63,2 & 36,8 \\
\hline & & & Doutorado & 12,5 & 87,5 & - & - & 58,3 & 41,7 \\
\hline & & & Total & 18,6 & 81,4 & - & - & 60,5 & 39,5 \\
\hline
\end{tabular}


Tabela 4 - Percepções de docentes da UnB sobre a reforma, por titulação e campo disciplinar: carreira nas universidades federais (\%)

\begin{tabular}{|c|c|c|c|c|c|c|c|c|c|}
\hline \multirow{2}{*}{$\frac{\circ}{2}$} & \multirow[b]{2}{*}{ Item } & \multirow[b]{2}{*}{ Campo } & \multirow{2}{*}{$\begin{array}{c}\text { Titula- } \\
\text { ção }\end{array}$} & \multicolumn{2}{|c|}{$\begin{array}{c}\text { Classificação } \\
\text { padrão }\end{array}$} & \multicolumn{2}{|c|}{$\begin{array}{l}\text { Contraste } \\
\text { discordância }\end{array}$} & \multicolumn{2}{|c|}{$\begin{array}{l}\text { Contraste } \\
\text { concordância }\end{array}$} \\
\hline & & & & Discordo & Concordo & $\begin{array}{l}\text { Discordo } \\
\text { totalmente }\end{array}$ & $\begin{array}{l}\text { Outras } \\
\text { opções }\end{array}$ & $\begin{array}{l}\text { Outras } \\
\text { opções }\end{array}$ & $\begin{array}{l}\text { Concordo } \\
\text { totalmente }\end{array}$ \\
\hline \multirow{27}{*}{ 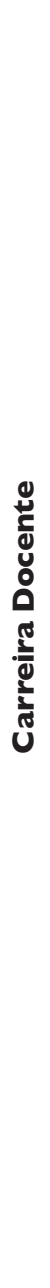 } & \multirow{9}{*}{$\begin{array}{c}\text { Isonomia } \\
\text { salarial deve } \\
\text { ser mantida } \\
\text { para } \\
\text { docentes das } \\
\text { universidades } \\
\text { federais }\end{array}$} & \multirow{3}{*}{$\begin{array}{l}\text { Todos } \\
(* *) ;[\times]\end{array}$} & Mestrado & 63,2 & 36,8 & 42,1 & 57,9 & - & - \\
\hline & & & Doutorado & 80,9 & 19,1 & 66,2 & 33,8 & - & - \\
\hline & & & Total & 74,5 & 25,5 & 57,5 & 42,5 & - & - \\
\hline & & \multirow{3}{*}{$\begin{array}{c}\text { C. } \\
\text { Duras }\end{array}$} & Mestrado & 73,7 & 26,3 & 47,4 & 52,6 & - & - \\
\hline & & & Doutorado & 79,5 & 20,5 & 61,4 & 38,6 & - & - \\
\hline & & & Total & 77,8 & 22,2 & 57,1 & 42,9 & - & - \\
\hline & & \multirow{3}{*}{$\begin{array}{l}\text { C. } \\
\text { Brandas } \\
(* *) ;[\times \times]\end{array}$} & Mestrado & 52,6 & 47,4 & 36,8 & 63,2 & - & - \\
\hline & & & Doutorado & 83,3 & 16,7 & 75,0 & 25,0 & - & - \\
\hline & & & Total & 69,8 & 30,2 & 58,1 & 41,9 & - & - \\
\hline & \multirow{9}{*}{$\begin{array}{c}\text { Dedicação } \\
\text { exclusiva deve } \\
\text { ser mantida } \\
\text { para docentes } \\
\text { das } \\
\text { universidades } \\
\text { federais }\end{array}$} & \multirow{3}{*}{$\begin{array}{c}\text { Todos } \\
\left\{{ }^{2}\right\}\end{array}$} & Mestrado & 18,4 & 81,6 & - & - & 60,5 & 39,5 \\
\hline & & & Doutorado & 17,6 & 82,4 & - & - & 36,8 & 63,2 \\
\hline & & & Total & 17,9 & 82,1 & - & - & 45,3 & 54,7 \\
\hline & & \multirow{3}{*}{$\begin{array}{c}\text { C. } \\
\text { Duras }\end{array}$} & Mestrado & 21,1 & 78,9 & - & - & 47,4 & 52,6 \\
\hline & & & Doutorado & 20,5 & 79,5 & - & - & 40,9 & 59,1 \\
\hline & & & Total & 20,6 & 79,4 & - & - & 42,9 & 57,1 \\
\hline & & \multirow{3}{*}{$\begin{array}{c}\text { C. } \\
\text { Brandas } \\
\{z\}\end{array}$} & Mestrado & 15,8 & 84,2 & - & - & 73,7 & 26,3 \\
\hline & & & Doutorado & 12,5 & 87,5 & - & - & 29,2 & 70,8 \\
\hline & & & Total & 14,0 & 86,0 & - & - & 48,8 & 51,2 \\
\hline & \multirow{9}{*}{$\begin{array}{l}\text { Quebra da } \\
\text { estabilidade } \\
\text { funcional } \\
\text { deve excluir } \\
\text { docentes das } \\
\text { univ. federais }\end{array}$} & \multirow{3}{*}{ Todos } & Mestrado & 58,3 & 41,7 & 38,9 & 61,1 & - & - \\
\hline & & & Doutorado & 67,6 & 32,4 & 45,6 & 54,4 & - & - \\
\hline & & & Total & 64,4 & 35,6 & 43,3 & 56,7 & - & - \\
\hline & & \multirow{3}{*}{$\begin{array}{l}\text { C. } \\
\text { Duras }\end{array}$} & Mestrado & 55,6 & 44,4 & 33,3 & 66,7 & - & - \\
\hline & & & Doutorado & 70,5 & 29,5 & 50,0 & 50,0 & - & - \\
\hline & & & Total & 66,1 & 33,9 & 45,2 & 54,8 & - & - \\
\hline & & \multirow{3}{*}{$\begin{array}{c}\text { C. } \\
\text { Brandas }\end{array}$} & Mestrado & 61,1 & 38,9 & 44,4 & 55,6 & - & - \\
\hline & & & Doutorado & 62,5 & 37,5 & 37,5 & 62,5 & - & - \\
\hline & & & Total & 61,9 & 38,1 & 40,5 & 59,5 & - & - \\
\hline
\end{tabular}

(**) Diferenças estatisticamente significativas ao nível de $5 \%$ - classificação padrão

[xx] Diferenças estatisticamente significativas ao nível de 5\% - contraste discordância (discordo totalmente/outras opçóes) \{zz\} Diferenças estatisticamente significativas ao nível de 5\% - contraste concordância (outras opçōes/concordo totalmente) 
outros custeios e capital -, ascenderam a cerca de $\mathrm{R} \$ 100$ milhões em 2001, ao passo que as verbas do tesouro - as do MEC - para o mesmo fim totalizaram apenas $\mathrm{R} \$ 40$ milhões, ou seja, menos de um terço do que a universidade despendeu nessa categoria (MARQUES; VELLOSO, 2003).

Nos quesitos sobre a carreira docente, $3 / 4$ dos informantes discordaram da manutenção da isonomia salarial no segmento universitário federal (tabelas 4). Os professores tomaram nítida posição contrária a uma das principais bandeiras do movimento docente de hoje e também da época em que os questionários foram aplicados, implicitamente preferindo uma das alternativas em discussão, todas envolvendo diferenciações salariais, seja entre a UnB e outras instituiçóes do País, seja no interior da própria universidade. $\mathrm{O}$ resultado não chegou a surpreender, pois reiterou preferência indicada seis anos antes, em pesquisa anterior abrangendo amostras de professores da UnB, na qual $61 \%$ dos docentes informaram que as complementaçôes salariais via convênios deveriam ser estimuladas (VELLOSO; MACHADO, 1994).

De outra parte, novamente por ampla maioria e em proporção um pouco maior que a anterior, os docentes posicionaram-se favoravelmente à manutenção do regime de trabalho de dedicação exclusiva nas federais, desta feita em consonância com um dos itens da agenda do movimento docente. No último item do bloco, e ainda uma vez com forte discordância em relação a mais um item da agenda do movimento docente, os professores opinaram contra excluir os docentes das federais da quebra da estabilidade funcional dos servidores, prevista na reforma do Estado da época e que afinal veio a consumar-se. Com efeito, quase $2 / 3$ dos professores se manifestaram a favor do rompimento da estabilidade funcional.

\section{Organização e gestão nas universidades: titulação e campo disciplinar}

Identificadas as principais tendências nas respostas dos docentes da UnB quanto a aspectos da reforma da educação superior associados à reforma do Estado, tratam-se agora de possíveis diferenças quanto a suas percepçōes por nível de titulação e campo disciplinar.

No quadro das percepções quanto à natureza estatal das federais, nota-se uma leve diferença entre mestres e doutores, considerada a classificação padrão; estes tenderam a ser mais desfavoráveis à alteração da referida natureza (75\%) que mestres (61\%); mas a significância estatística do resultado alcança apenas o nível de $10 \%$, não sugerindo confiança suficiente na diferença registrada (tabela 1). Ainda na mesma classificação padrão, quando se efetua o controle por campo disciplinar, entre mestres e doutores as diferenças aumentam nas Ciências Brandas e diminuem nas Ciências Duras. Se com tal controle os resultados alcançassem nível de significância aceitável, as diferenças naquele campo disciplinar seriam as responsáveis pelas que foram inicialmente registradas no conjunto de ambos os campos, mas a significância novamente se situa no nível de $10 \%$, sem o padrão de confiabilidade aceitável. Também não se registram diferenças significativas no outro tipo de classificação das respostas para a variável, aqui denominado contraste discordância.

No debate nacional sobre as concepções da universidade que se deseja, a proposição de que cada qual deve seguir sua vocação surge pela primeira vez em meados dos anos 
oitenta, no relatório do Grupo Executivo para a Reformulação do Ensino Superior Geres, comissão instituída no MEC. A proposta distinguia as "universidades de ensino" das "universidades de pesquisa", ambas, como os nomes indicam, desfrutando dos mesmos privilégios de uma instituição universitária. A distinção legitimaria o título de universidade concedido a todas as que o possuíssem, mesmo que não fizessem pesquisa; por isso, era extremamente bem-vinda pelas universidades particulares, pois nestas, com raras exceções, não se faz pesquisa. A Lei de Diretrizes e Bases da Educação de 1996 redefiniu parcialmente a questão, estabelecendo que toda universidade deve ter pesquisa institucionalizada, e a matéria viria ser posteriormente regulamentada pelo Conselho Nacional de Educação.

O quesito sobre a vocação - ou especialização de funções - da universidade é reflexo do debate iniciado com o Geres. Quando as respostas para esse item são organizadas segundo a classificação padrão adotada no estudo, no conjunto da universidade não se observam diferenças significativas entre níveis de titulação. Mas, quando numa categoria se situam os docentes que concordaram totalmente com o enunciado e, na outra, todos os demais, surgem divergências com significância no nível de 5\%; nesse tipo de contraste, aqui chamado de contraste concordância, doutores são bem mais favoráveis que mestres à especialização de funçôes das universidades. Como os docentes bem mais afinados com a proposição são doutores, que costumam ter maior envolvimento com atividades de investigação, é provável que sua preferência se volte para o modelo de universidade de Humboldt, no qual a pesquisa tem preeminência.

Entretanto, quando são introduzidos controles por campo disciplinar, no mesmo tipo de contraste, verifica-se que as diferenças significativas subsistem apenas nas Ciências Brandas $(\mathrm{p}<=0,05)$. Nesse campo, a distância entre mestres e doutores é da ordem de quatro: cerca de $40 \%$ destes estão plenamente convictos de que cada universidade deve especializar-se no ensino, pesquisa ou extensão, conforme sua vocação. Nas áreas que integram esse campo, mestres, bem mais que doutores, estariam mais próximos do modelo de universidade no qual as suas três funções - ensino, pesquisa e extensão se encontram relativamente equilibradas. Esses resultados indicam que a disparidade antes observada para o conjunto dos campos se deve sobretudo às percepçóes dos docentes das Brandas. Nesse campo, é possível que doutores, comparativamente a mestres, preocupem-se mais em situar-se na defesa de uma universidade na qual a pesquisa tenha seu espaço preservado. A força dos paradigmas dominantes nas Ciências Duras, que desfrutam de maior grau de consenso que nas Brandas, possivelmente teria aproximado as percepçôes de mestres e doutores naquele campo.

Ao contrário do que ocorreu com o tema anterior, o cenário das opinióes de mestres e doutores mostrou-se bastante homogêneo quanto à proposta da criação de novas organizações no processo de reestruturação da educação superior (principalmente Organizações Sociais - OS). Seja no conjunto dos docentes, seja no interior de cada campo disciplinar, não se constataram diferenças significativas por nível de titulação na classificação padrão nem no contraste concordância. Esse cenário, assim como alguns outros adiante comentados, parece encontrar explicação na análise de Balbachevsky (2000a, 2000b), cuja pesquisa classificou as instituições de ensino superior brasileiras em três tipos de contextos: semi-acadêmico, semi-empresarial e semicorporativo. Nestes, a 
autora encontrou três subculturas acadêmicas dominantes, originárias de ambientes da organização do trabalho, dos interesses e valores dos professores. No contexto semiacadêmico, prevalece a subcultura do "professor-pesquisador", que tende a incluir a docência como parte do papel maior de investigador, e cujo principal elemento de prestígio está no reconhecimento pela comunidade de pares, em função da produção em pesquisa. Nas instituiçôes semi-acadêmicas, geralmente há fortes pressões para socializar os professores de menor titulação na perspectiva profissional dos docentes-pesquisadores. Em decorrência disso, nessas instituições, haveria boa semelhança entre as percepções de mestres e de doutores quanto a variados aspectos da vida acadêmica - e conseqüentemente, no caso do presente estudo, também quanto a diversas diretrizes da reforma universitária. Este seria o caso da $\mathrm{UnB}$, na qual a pesquisa identificou a predominância da subcultura do professor-pesquisador. Assim, a homogeneidade de opiniões de mestres e doutores sobre as OS encontraria raízes na subcultura mais vigorosa na instituição.

As respostas ao quesito sobre gestão não evidenciaram diferenças por titulação quando organizadas na classificação padrão, mas apareceram discrepâncias com significância estatística no contraste discordância (tabela 2). Neste, 47\% dos mestres disseram estar totalmente convencidos de que as universidades não devem ser administradas por profissionais fora do quadro docente, parcela bem maior que os $28 \%$ de doutores que informaram pensar da mesma forma. Uma possível interpretação para esse resultado pode apoiar-se na concepção de Cox e Courard (1990) para a gestão da universidade, uma organização complexa e especializada e que se define pela articulação dinâmica de duas dimensôes, a disciplinar e a empresarial. A dimensão disciplinar está voltada para a descoberta e difusão do conhecimento, que continuamente geram desordem no sentido acadêmico do termo; esta, por seu turno, está associada à liberdade acadêmica indispensável para a reflexão crítica e geração de conhecimento novo. $\mathrm{O}$ avanço da dimensão disciplinar só pode ter êxito se gerido pela autoridade acadêmica, cujo poder é dado pelo reconhecimento dos pares, e implica uma gestão com órgãos colegiados. Já a dimensão empresarial orienta-se para a coordenação no sentido da produção da ordem, do ponto de vista administrativo, estando associada a uma gestão de corte burocrático. Nesse estilo de gestão, prevalece um tipo de autoridade geralmente delegada e legitimada pelos docentes e/ou pelo Estado, no qual se busca o melhor emprego dos recursos para diversos fins e que competem entre si pelas verbas disponíveis.

As universidades, como instituições de produção e difusão do saber, precisam apoiar-se no primeiro tipo de autoridade e de gestão para atingir suas finalidades. Como instituições complexas que são, também não podem prescindir do segundo tipo de autoridade e de gestão. A convivência desses estilos conflitantes entre si é da natureza da universidade moderna. Se o primeiro exclui o segundo, a instituição não sobrevive enquanto organização complexa. Se o segundo superpõe-se ao primeiro, a instituição abdica de sua função propriamente universitária, enquanto instância privilegiada de reflexão crítica, de difusão e produção de conhecimento. Nesse quadro da discussão sobre os dois estilos de gestão, pode-se dizer que a proposição de contratar administradores profissionais para gerir a universidade, tal qual enunciada no questionário aos docentes, implicitamente continha referência ao segundo, o de cunho empresarial. Nesse quadro, os dados mostraram 
que doutores, bem menos que mestres, tinham menor receio deste estilo de gestão e provavelmente estavam mais preocupados com um melhor emprego dos recursos disponíveis. É possível que doutores, tendo passado por um mais longo processo de formação que mestres, tenham internalizado melhor os paradigmas e/ou as culturas disciplinares predominantes em seus campos de atuação e, por isso, estivessem mais confiantes em que, na busca da eficiência na gestão, as formas vigentes de produzir e difundir conhecimento, assim como os padrões adotados para organizar e implementar o ensino, seriam imunes à administração de profissionais externos ao quadro da universidade.

Quando são feitos controles por campo disciplinar, as diferenças por nível de titulação permanecem visíveis, mas não alcançam significância estatística. Esse parece ser um caso nítido de efeitos do tamanho da amostra face a diferenças registradas. Nos resultados no contraste discordância para o conjunto da amostra, a diferença entre mestres e doutores que foram totalmente contrários ao enunciado é de 19 pontos percentuais. Em cada um dos dois campos essa distância é estatisticamente idêntica, de 18 pontos percentuais. Entretanto, como se sabe, quanto menor a amostra, maior precisa ser a diferença para que esta alcance significância estatística. No caso em apreço, o tamanho do conjunto da amostra cai drasticamente quando se analisa em separado cada um dos dois campos disciplinares. Tem-se assim o paradoxo estatístico de que mestres e doutores manifestaram opiniōes que são significativamente diferentes no conjunto da amostra, porém não são significativamente diversas dentro de cada um dos campos que integram esse conjunto.

\section{Financiamento e carreira nas universidades federais}

Os dados sobre os dois quesitos acerca do financiamento das universidades federais estão apresentados na tabela 3. Nesse bloco, observa-se notável homogeneidade de opiniōes entre mestres e doutores, seja na classificação padrão, seja no contraste concordância. As respostas aos dois quesitos, que foram amplamente favoráveis à cobrança de taxas nos cursos de especialização - convalidando práticas já estabelecidas na UnB e também fortemente a favor da noção de autonomia que envolve geração de recursos próprios, não distinguiram mestres de doutores.

No item que se refere aos recursos próprios, certamente as respostas foram influenciadas pela consciência quanto à importância dessas verbas no orçamento da $U n B$, bastante difundida entre os professores e geralmente ligada à imagem do patrimônio da universidade. Afinal de contas, os grandes blocos residenciais da Colina, dentro do campus, estão à vista de todos os que por ele transitam, e neles reside apreciável contingente de professores, que alcança a casa dos 400, além de cerca de 150 funcionários técnico-administrativos. Embora o aluguel dos imóveis provavelmente tenha sido a primeira fonte de recursos próprios que acudiu à memória dos docentes que responderam ao questionário, a maior parte das verbas próprias da UnB desde há muitos anos advém do Centro de Seleção e Promoção de Eventos - Cespe, cabendo aos aluguéis fração menor que $10 \%$ nas receitas geradas pela universidade (VELLOSO; MARQUES, 2005).

No bloco sobre a carreira dos professores nas federais (tabela 4), as respostas ao item sobre a quebra da estabilidade funcional, tanto na classificação padrão quanto no 
contraste discordância, não evidenciaram divergências significativas por nível de titulação, tal como ocorreu com os dois quesitos sobre financiamento (tabela 3). Nas respostas sobre o rompimento da estabilidade, que foram majoritariamente contrárias à exclusão do corpo docente dessa parte da reforma do Estado, cabe assinalar o corte profissional e não corporativo das preferências indicadas.

O padrão das respostas a esses três quesitos sobre a universidade federal - taxas na especialização, recursos próprios e estabilidade funcional - merece ser lido em conjunto com dados sobre as novas formas de organização institucional, no bloco sobre a organização da educação superior, da tabela 1 . Em todos esses quatro quesitos não houve divergências significativas nas respostas por titulação. Essa homogeneidade de percepções registrada parece apoiar a análise de Balbachevsky (2000a), que classificou a UnB como uma instituição de tipo semi-acadêmico, na qual predomina a subcultura do professorpesquisador, antes discutida; nessa dominância aparentemente residiria a homogeneidade de percepções que se constatou.

A dominância dessa subcultura, entretanto, não teria tido força suficiente para se sobrepor a outros fatores no caso das percepçóes sobre a isonomia salarial para professores das federais (tabela 4). Nesse quesito, as opinióes de mestres e doutores foram nitidamente distintas, tanto na classificação padrão quanto no contraste discordância, e sempre com um nível de significância de 5\%. De fato, no conjunto do corpo docente, essa questão constituiu um claro divisor de águas por nível de titulação. É bem verdade que, em ambos os segmentos, a maioria elegeu opções contrárias à paridade salarial - uma destacada bandeira do movimento sindical docente -, seja entre mestres (63\%), seja entre doutores (81\%), como mostram os dados da classificação padrão. Mas, como ilustram com intensidade ainda maior os resultados para o contraste discordância, $66 \%$ dos doutores informaram que estavam totalmente convictos quanto às diferenciações salariais que deveriam prevalecer para níveis idênticos da carreira docente, no interior da $\mathrm{UnB}$ ou entre universidades, ao passo que apenas $42 \%$ dos mestres declararam essa mesma opinião.

No entanto, a introdução de controles por campos disciplinares revela que as diferenças de opinião sobre a isonomia salarial tendem a ser bem maiores nas Ciências Brandas, e é só nesse campo que elas têm significado estatístico. Com esses controles, quando os resultados são apresentados na classificação padrão, as percepçōes de mestres e doutores das Ciências Duras mostram-se bem parecidas; as diferenças só se tornam visíveis no contraste discordância, mas elas não chegam a ser estatisticamente significativas. Nesse campo, a prevalência de paradigmas informados por um maior grau de compartilhamento entre pares e de culturas disciplinares algo mais homogêneas atenuaria as diferenças por nível de titulação. Uma das notáveis diferenças quanto a modos de fazer ciência, dominantes num e noutro campo - e portanto das culturas disciplinares a eles associadas -, diz respeito à natureza dos projetos de pesquisa e, conseqüentemente, ao tipo de colaboração entre orientadores e orientandos em atividades de investigação. Essas diferenças refletem-se, por exemplo, na participação de orientandos em projetos de pesquisa de seus orientadores. Dados para estudantes de doutorado no País indicam que, nas Ciências Exatas e da Terra e nas Ciências Biológicas, aproximadamente 50\% e 60\% dos doutorandos, respectivamente, fazem teses que integram projetos de pesquisa de seus orientadores, ao passo que, nas Ciências Humanas e nas Ciências Sociais Aplicadas, a 
proporção correspondente é menor que 20\% (VELLOSO; VELHO, 2001). Esse tipo de participação, naturalmente, tende a fortalecer a hierarquia acadêmica desde o início da formação pós-graduada e, conseqüentemente, a robustecer considerações de mérito acadêmico na carreira docente e na remuneração, as quais se opõem, intrinsecamente, a princípios de isonomia salarial.

Já nas Ciências Brandas, características dominantes nesse campo, em especial as que incluem em algumas áreas a valorização de aspectos outros que não o mérito acadêmico, como o impacto social da pesquisa e do ensino, contribuiriam para gerar as significativas diferenças por nível de titulação. Entre doutores, no agrupamento do contraste discordância, - dos docentes manifestaram-se totalmente contrários à isonomia salarial, enquanto entre mestres a fração correspondente foi menor que $40 \%$. Esses resultados possivelmente sugerem que, em matéria de carreira docente, os doutores, com engajamento mais intenso na produção do conhecimento, tenderiam a atribuir maior valor ao mérito acadêmico, ao passo que os mestres estariam mais propensos a considerar critérios formais e supostamente igualitários de remuneração docente. Também não se pode descartar a hipótese, sem excluir a anterior, de que uma menor participação dos mestres em atividades de pesquisa - em virtude de seu nível de formação pós-graduada - corresponda a maior envolvimento com o movimento sindical docente e, portanto, a maior aderência às bandeiras por este empunhadas.

No quesito sobre a manutenção do regime de trabalho de dedicação exclusiva para os docentes das federais, não se constatam diferenças por nível titulação na classificação padrão, porém elas se delineiam com nitidez e com significância estatística no contraste discordância $(\mathrm{p}<=0,05)$. Nesse formato de agregação das respostas, mais de $60 \%$ dos doutores declararam ser totalmente favoráveis à manutenção da dedicação exclusiva $\mathrm{DE}$, contra apenas $40 \%$ dos mestres.

O regime de DE foi gradativamente implantado a partir dos anos 70 , após a reforma da educação superior de 1968, como já indicado anteriormente. Fortalecendo a profissionalização da carreira docente, conduziu a profundas transformações na fisionomia da universidade pública brasileira, notadamente nas federais. $\mathrm{O}$ antigo panorama no qual figurava o professor de tempo parcial - o profissional que exercia suas principal atividade fora dos muros da academia - progressivamente deu lugar ao cenário do corpo docente em tempo integral ou $\mathrm{DE}$ - no qual aquele profissional passaria a ser menos a regra e mais a exceção. Desdobramentos desse cenário, compreendendo o aumento do número de docentes pós-graduados - inicialmente, mestres, depois, doutores -, além da expansão dos programas de pós-graduação ${ }^{8}$ e a própria implantação e expansão do regime de $\mathrm{DE}$, uns associados aos outros, estão entre os principais fatores imediatamente responsáveis pela consolidação e concentração da pesquisa nas universidades públicas. Ainda que notável ampliação da dedicação exclusiva e da capacitação docente, que propiciou tempo, remuneração e qualificação para a atividade de pesquisa, também tenha permitido situações como a identificada pelo estudo de Guimarães e Caruso (1996), que constatou a existência de doutores em DE que nunca escreveram uma única linha de livro ou artigo publicado, nem realizaram qualquer outro tipo de produção acadêmica divulgada - estes casos, muito mais a exceção do que a regra -, o fato é que tal regime de trabalho teve marcante contribuição para a profissionalização da carreira acadêmica. 
$\mathrm{Na} \mathrm{UnB}$, a grande maioria do quadro docente está contratada em $\mathrm{DE}$, não havendo expressiva variação por nível de titulação quanto a esse tipo de regime de trabalho (mestres, 86\%; doutores, 95\%). Assim, as respostas obtidas no contraste concordância, no qual a maioria de doutores mostrou-se plenamente convicta quanto à importância de manter esse regime, enquanto só uma minoria de mestres partilhou da mesma opinião, não podem ser atribuídas a preferências que decorreriam do regime de trabalho no qual cada um desses dois grupos de titulação desenvolve suas atividades universitárias. Antes, tais diferenças provavelmente se associam a distintas percepções quanto às condições necessárias para o desenvolvimento de atividades universitárias adicionais ao ensino. Para doutores, por exemplo, a noção de que é necessário assegurar tempo remunerado para a realização de atividades de investigação, de pesquisa e desenvolvimento, ou de produção artística e cultural inovadora, para além do ensino, pode ter orientado o padrão de respostas distinto do registrado para mestres.

Ainda uma vez, entretanto, quando são efetuados controles por campo disciplinar, altera-se o panorama no contraste concordância: as diferenças por titulação só têm significado estatístico nas Ciências Brandas. Nesse campo, 71\% dos doutores foram plenamente favoráveis à manutenção do regime de $\mathrm{DE}$ e somente $26 \%$ dos mestres assinalaram essa opção. No interior das Ciências Duras, as opiniōes por nível de titulação são muito parecidas, variando pouco em torno de $57 \%$ para os dois grupos, e a ausência de diferenças certamente não pode ser atribuída à drástica redução do tamanho da amostra quando são feitos controles por campo disciplinar. Tudo indica que o quadro anterior para o conjunto da amostra, no caso da dedicação exclusiva, devia-se exclusivamente - ou quase - às significativas distâncias de percepções de mestres e doutores das áreas que integram as Brandas.

\section{NOTA FINAL}

O estudo analisou percepções de docentes da UnB quanto a questóes da reforma da educação superior do final dos anos 90 . Boa parte dessas questôes situava-se no bojo da reforma do Estado que se desenhava e que veio a consumar-se. Mas entre os temas em discussão sobre a educação superior foram pouquíssimas as propostas que chegaram a ser implementadas; em 2004, quando se discute a chamada "reforma da universidade" do governo Lula, a maioria delas ainda tem relevância para o debate. As análises foram feitas com base na hipótese de que mestres e doutores tenderiam a ter percepções diferenciadas quanto às referidas questôes e que a inserção em campos disciplinares distintos também afetaria essas percepções. Nesta seção, retomam-se os principais resultados obtidos e indicam-se brevemente as tendências maiores que foram registradas.

Os dados obtidos não apontaram para um nítido padrão de respostas por nível de titulação, mas por vezes sugeriram certas tendências quanto a campos disciplinares ou, então, indicaram possíveis influências de culturas acadêmicas dominantes. Em algumas questões da reforma da educação superior da época, a marca da titulação simplesmente inexistiu, isto é, não se registraram diferenças estatisticamente significativas entre as percepçōes de mestres e doutores. Docentes com ambos os níveis de titulação foram favoráveis, por exemplo, à criação de novas organizações para reestruturar a educação superior 
- as chamadas organizaçōes sociais, que, aliás, não vingaram com a desenvoltura esperada pela reforma do Estado. Esse foi igualmente o caso das respostas a três outras questões que diziam respeito diretamente à universidade federal, nas quais também não houve diferenças significativas conforme a titulação: os professores foram favoráveis à cobrança de taxas em cursos de especialização, convalidando práticas já existentes; manifestaram seu acordo com uma concepção de autonomia envolvendo a geração de recursos próprios, aspecto tão fundamental quanto o anterior para sobrevivência financeira da instituição; concordaram com o rompimento da estabilidade funcional de servidores públicos, incluindo os docentes das federais, o que afinal veio materializar-se no âmbito da reforma do Estado.

Em pesquisa antes discutida, as instituiçōes brasileiras de educação superior foram classificadas em termos da presença maior ou menor da autoridade acadêmica e das subculturas dominantes, inserindo-se em três tipos de contextos: semi-acadêmico, semicorporativo e semi-empresarial. A UnB foi situada no contexto semi-acadêmico, no qual a lógica da autoridade acadêmica tende a predominar, associada à subcultura do docentepesquisador. É provável que os resultados descritos no parágrafo anterior, com padrão bastante indiferenciado de respostas entre os dois grupos de titulados, encontrem explicação na dominância dessa subcultura, que teria aproximado percepções de mestres e doutores quanto às questôes referidas.

Já em outras questões da reforma da educação superior, os efeitos de tal subcultura seriam mais débeis, sendo superados por outros. Esse parece ter sido o caso de dois itens referentes à organização da educação superior e de dois outros relativos à carreira docente; para todos, registraram-se diferenças significativas por nível de titulação, no conjunto dos docentes entrevistados na UnB. No primeiro caso, a hipótese de que as universidades federais deixassem de ser estatais foi rechaçada mais por mestres que por doutores. De modo análogo, estes, mais que aqueles, indicaram ter maior grau de concordância com conceito de universidade com ênfases em funções diferenciadas, conforme a respectiva vocação - pesquisa, ensino ou extensão. Em ambos os casos, entretanto, quando os dados foram analisados dentro de cada campo disciplinar, prevaleceram distâncias significativas apenas para os docentes das áreas das Ciências Brandas. $\mathrm{O}$ mesmo comportamento foi observado no caso da manutenção da isonomia salarial e da dedicação exclusiva para os docentes das federais: a marca da titulação, que tinha significância estatística no conjunto da amostra, se diluiu no campo das Ciências Duras e se manteve no campo das Ciências Brandas. Esse padrão de resultados sugere que os modos de fazer ciência (e tecnologia) no campo das Duras - os paradigmas na acepção de Kuhn -, desfrutando de maior grau de consenso entre pares, assim como as culturas disciplinares que tendem a prevalecer, algo mais homogêneas, socializariam os docentes no sentido de uma maior convergência de convicçôes dos mestres e doutores com respeito às questōes referidas, ao passo que, nas Brandas, devido às suas características disciplinares, tais efeitos não se fariam sentir.

Em suma, a subcultura do professor-pesquisador, que tende a prevalecer em instituições semi-acadêmicas como a UnB, o nível de consenso de paradigmas disciplinares e a natureza das culturas dos campos disciplinares parecem se entrelaçar com diferentes tipos de efeito e graus de intensidade, freqüentemente anulando a marca da titulação, conforme a questão de reforma da educação superior que seja posta em discussão. 
Compreender melhor por que e como esses processos ocorrem demandaria considerar aspectos adicionais, ocupando mais espaço que o permitido para o presente artigo e, em boa parte dos casos, exigiria estudos ulteriores. Espera-se que os resultados contribuam para uma melhor compreensão do que pensavam os docentes da UnB sobre a reforma da educação superior do final da década passada, a qual tem diversos pontos de interseção com a que se discute em 2005.

\section{Notas}

1. Como diz Kuhn (1970, p. 181), referindo-se à $1^{a}$ edição de sua obra, "um leitor com simpatia pelo texto, e que partilha de minha convicção de que [o conceito de] 'paradigma' é um dos elementos filosóficos centrais do livro, [...] concluiu que o termo foi usado em pelo menos vinte e duas diferentes acepçóes". Embora reconheça certa elasticidade conceitual, Kuhn prossegue informando que "a maioria dessas diferenças [...] se deve a inconsistências lingüísticas" (idem).

2. Doravante serão referidas como questóes da reforma da educação superior.

3. Numa outra perspectiva, o estudo de Rocha (2000) comparou percepçóes de professores doutores, não titulares, com as de professores titulares; o de Aragón (2000) discutiu o perfil do corpo docente e a participação em projetos de pesquisa, entre outros aspectos.

4. Veja-se também a discussão em Velloso (1996) no caso das universidades brasileiras.

5. Supondo, é claro, que a distribuição seja retangular, ou pelo menos aproximadamente normal. Pontos de corte como mencionado não são apropriados para distribuições muito assimétricas, conforme adiante se discute.

6. Menos de $8 \%$ dos docentes da UnB têm titulação máxima de graduado ou especialista.

7. Suprimiu-se do campo das C. Brandas a área de Artes, que não se enquadrava na proposta do autor. $\mathrm{Na}$ classificação do autor, na UnB em 1998 as áreas das C. Duras-Puras situavam-se nas seguintes unidades: Instituto de Física; Departamento de Geoquímica; Departamento de Química; Departamento de Biologia Celular; Departamento de Geologia Geral e Aplicada e Departamento de Matemática; as áreas das C. Duras-Aplicadas, nos departamentos e faculdades a seguir: Departamentos de Engenharia Elétrica, Civil, Mecânica e Florestal; Departamento de Estatística; Departamento de Botânica; Departamento de Zoologia; Departamento de Ecologia; Departamento de Fitopatologia; Faculdade de Agronomia e Veterinária; Departamento de Genética e Morfologia; Departamento de Clínica Médica e Cirúrgica; Departamento de Odontologia; Departamento de Computação. As C. Brandas-Puras localizavam-se em seis departamentos - Economia, Geografia, História, Filosofia, Sociologia e Antropologia -, e as C. BrandasAplicadas, num número bem maior de unidades: Instituto de Psicologia, Faculdade de Educação; Departamento de Administração; Departamento de Nutrição; Departamento de Saúde Coletiva; Departamento de Serviço Social; Departamento de Informação e Documentação; Faculdade de Direito; Departamento de Relações Internacionais; Departamento de Ciência Política; Departamento de Língua Estrangeira e Tradução, Linguística Clássica e Vernácula e Teoria Literária e Leitura.

8. A propósito da instalação do sisttema de pós-graduação no País, na esteira da atuação das primeiras agências de fomento nos anos 60, veja-se Martins e Velloso (2003).

\section{Referências}

AMARAL, Nelson Cardoso. Financiamento da educação superior. Estado versus mercado. São Paulo: Cortez e Edunimep, 2003.

ARAGÓN, Virgilio Alvarez. La profesión académica en Brasil: el caso de la Universidad de Brasilia. In: SCHMIDT, Benicio Viero; OLIVEIRA, Renato de; ARAGÓN, Virgilio Alvarez (Orgs.). Entre escombros e alternativas. ensino superior na América Latina. Brasília: Edunb, 2000. p. 179-204.

.; ROCHA, Maria Zélia Borba; MATOS, Bráulio Tarcísio Pôrto de. Políticas públicas e profissão acadêmica no Brasil. Brasília: Universidade de Brasília, 1997. Mimeografado. 
BALBACHEVSKY, Elisabeth. A profissão acadêmica no Brasil: as múltiplas facetas do nosso sistema de ensino superior. Brasília: Funadesp, 2000a.

A profissão acadêmica no Brasil: condiçôes atuais e perspectivas para o futuro. In: SCHMIDT, Benicio Viero; OLIVEIRA, Renato de; ARAGÓN, Virgilio Alvarez (Orgs.). Entre escombros e alternativas: ensino superior na América Latina. Brasília: Edunb, 2000b. p. 139-154.

BECHER, Tony. Las disciplinas y el académico. Universidad Futura, Mexico, v. 4, n. 10, p. 56-71, 1992.

BOURDIEU, Pierre. O campo científico. In: ORTIZ, Renato (Org.). Grandes cientistas sociais. São Paulo: Ática, 1994. p. 123-155.

BRESSER-PEREIRA, Luís Carlos. A reforma do aparelho do Estado e a Constituiçāo brasileira. Conferência nos Seminários sobre a Reforma Constitucional. Brasília: Presidência da República, 1995. Mimeografado.

CLARK, Burton. El sistema de educación superior - una visión comparativa de la organización académica. México: Nueva Imagen, 1983.

COWEN, Robert. Grã-Bretanha - políticas multiplicadoras das universidades: nota sobre tecnologias sociais. In: MORHY, Lauro et al. (Orgs.). Universidade no mundo: universidade em questão, v. 2. Brasília: Edunb, 2004. p. 271-292.

COX, Cristián; COURARD, Hernán. Autoridad y gobierno en la universidad chilena (1950-1989): categorías de análisis y desarrollo histórico. In: COX, Cristián (Org.). Formas de gobierno en la educación superior. nuevas perspectivas. Santiago, Chile: Flacso, 1990.

CUNHA, Luiz Antônio. A universidade reformanda. Rio de Janeiro: F. Alves, 1988.

GATTO, Patricia. Percep̧ôes de docentes sobre o ensino superior: um estudo na Universidade de Brasília. Brasília, 2002. Dissertação (mestrado), Faculdade de Educação da Universidade de Brasília.

GUIMARĀES, Reinaldo; CARUSO, Nádia. Capacitação docente: o lado escuro da pós-graduação. In: FUNDAÇÃO CAPES (Org.). Discussāo da pós-graduação brasileira. Brasília: Fundação Capes, 1996. p. 117-126.

KUHN, Thomas. The structure of scientific revolutions. 2. ed. Chicago: The University of Chicago Press, 1970. MARTINS, Carlos Benedito; VELLOSO, Jacques. Balanço: as universidades privadas no contexto do ensino superior contemporâneo. In: HEYMANN, Luciana; ALBERTI, Verena (Orgs.). Trajetórias da universidade privada no Brasil, v. 2. Brasília: Fundação Capes e Rio de Janeiro: CPDOC - Fundação Getúlio Vargas, 2003. p. 797-827. NEAVE, Guy; VAN VUGHT, Frans. Conclusion. In: NEAVE, Guy; VAN VUGHT, Frans (Orgs.). Prometheus bound: the changing relationships between government and higher education in Western Europe. New York: Pergamon Press, 1991. p. 239-255.

ROCHA, Maria Zélia Borba. Políticas públicas e acadêmicos: um caso de impacto. In: SCHMIDT, Benicio Viero; OLIVEIRA, Renato de; ARAGÓN, Virgilio Alvarez (Orgs.). Entre escombros e alternativas: ensino superior na América Latina. Brasília: Edunb, 2000. p. 205-227.

SCHWARTZMAN, Jacques. Questóes de financiamento nas universidades brasileiras. Belo Horizonte: Universidade Federal de Minas Gerais, 1998. Mimeografado.

VELHO, Léa. Pós-graduação em Ciências Sociais e Humanidades: por quê e em que elas diferem das Ciências Naturais? In: VELLOSO, Jacques (Org.). O ensino superior e o Mercosul. Rio de Janeiro: Garamond e Unesco, 1998. p. 99-111. VELLOSO, Jacques. Universidade pública, financiamento e reforma do Estado. In: TRINDADE, Hélgio; LUCE, Maria Beatriz (Orgs.). Mudança e desenvolvimento da universidade pública na América Latina. Anais. Brasília: Andifes, 1996. p. $105-120$.

. Universidade na América Latina: rumos do financiamento. Cadernos de Pesquisa, São Paulo, n. 110, p. 39-66, jul. 2000.

.; MACHADO, Lia Zanotta. Universidades públicas: gestão política e financeira. Faculdade de Educação e Departamento de Antropologia, Universidade de Brasília, 1994. 61 p. Mimeografado.

.; MARQUES, Paulo Marcello Fonseca. Recursos próprios da Universidade de Brasília, o financiamento das IFES e a reforma da educação superior. Educação e Sociedade. Campinas, 2005, no prelo.

.; VELHO, Léa. Mestrandos e doutorandos no País: trajetórias de formação. Brasília: Fundação Capes,

2001. 


\section{Higher education policies and disciplinary fields: perceptions of faculty members of the Universidade de Brasília}

Abstract

The study discusses perceptions of faculty members of the Universidade de Brasilia on issues of higher education policies in the late nineties; a number of these are still germane to the so-called "university reform "project of the incumbent Lula government. Data were obtained by means of a 10 percent random sample of faculty members. Analyses were done under the hypothesis that masters and doctors would have different perceptions regarding the mentioned issues and that disciplinary fields in which they worked would also affect their perceptions. On some issues, and particularly for faculties in the field of humanities and social sciences, significant differences were found by degree held, as in the case of equal salaries for the same job, more favored by masters, or in the case of full time employment, to which doctors gave larger importance. However, no significant differences were found on most of the issues discussed, suggesting that an academic subculture predominates among faculty members of the university.

Keywords: Higher education policies. University reform. Universidade de Brasilia. Faculty. Masters. Doctors. Disciplinary fields.

\section{Les politiques de l'enseignement supérieur et les champs disciplinaires : les perceptions des professeurs de l’Universidade de Brasília}

Résumé

L'étude discute les perceptions des professeurs de l'Université de Brasilia quant aux politiques pour l'éducation supérieure de la fin des années 1990, étant donné qu'une bonne partie est encore valable pour le projet de la supposée réforme de l'université du gouvernement Lula. Les données ont été obtenues par un échantillon aléatoire de 10 $\%$ des professeurs de linstitution. Les analyses ont été faites ayant comme base l'hypothèse que les maîtres et docteurs auraient tendance à avoir des perceptions différentiées quant aux questions mentionnées et que l'insertion des champs disciplinaires distincts auraient aussi un effet sur ces perceptions. En ce qui concerne certaines questions, et principalement dans le champs des humanités et des sciences sociales, des différences significatives ont été rencontrées par niveau de titulation, comme dans le cas de l'isonomie salarielle plus favorisée par les maîtres ou dans le cas de la dédication exclusive à laquelle les docteurs attribuent une plus grande importance. Néanmoins, la majorité des réponses aux questions apprésentent aucune différence, suggérant la prédominance d'une sub-culture académique dans l'institution.

Mots clefs : Politiques de l'enseignement supérieur. Réforme universitaire. Université de Brasilia. Professeurs. Maîtres. Docteurs. Champs disciplinaires.

\section{Políticas para la enseñanza superior y campos disciplinares: percepciones de docentes de la Universidade de Brasília}

\section{Resumen}

Ese estudio discute percepciones de docentes de la Universidade de Brasilia em relación a cuestiones de las politicas para la educación superior de finales de los años 90, gran parte de ellas todavía relevantes para el proyecto de la "reforma de la universidad" del gobierno Lula. Los datos fueron obtenidos através de una muestra aleatoria de un 10\% de los profesores de la institución. Los análisis fueron hechos a partir de las hipótesis de que maestros y doctores tenderían a tener percepciones diferenciadas em relación a las referidas cuestiones y que la inserción en campos disciplinares distintos también afectaría esas percepciones. En algunas cuestiones, y principalmente en el campo de las humanidades e de las ciencias sociales, se encontraron diferencias significativas em función del nivel de titulación, como en el caso de la isonomia salarial, más favorecida por los maestros, o en el caso de la dedicación exclusiva, a la cual los doctores atribuyen mayor importancia. Sin embargo, en la mayoría de las cuestiones las respuestas fueron indiferenciadas, sugeriendo el predominio de una subcultura académica en la institucion.

Palabras-clave: Políticas de enseñanza superior. Reforma universitaria. Universidade de Brasília. Docentes. Maestros y doctores. Campos disciplinares.

Recebido: 09.02.2005

Aceito: 15.04.2005 


\title{
FINANCIAMENTO DA EDUCAÇÃO DO BRASIL: DA VINCULAÇÃO CONSTITUUCIONAL Ã CONSTRUÇÃOO DE UMA ESCOLA COM PADRÕES MÍNIMOS DE QUALIDADE
}

\author{
FINANCING OF EDUCATION IN BRAZIL: FROM THE \\ CONSTITUTIONAL BINDING TO THE CONSTRUCTION \\ OF A SCHOOL OF MINIMUM QUALITY STANDARDS \\ LE FINANCEMENT DE L'ÉDUCATION AU BRÉSIL : DE \\ L'EXIGENCE CONSTITUTIONNELLE À LA CONSTRUCTION \\ D’UNE ÉCOLE AVEC DES NIVEAUX MINIMES DE QUALITÉ \\ FINANCIACIÓN DE LA EDUCACIÓN EN BRASIL: DE LA \\ VINCULACIÓN CONSTITUCIONAL A LA CONSTRUCCIÓN \\ DE UNA ESCUELA CON PATRONES MÍNIMOS DE CUALIDAD
}

José Marcelino de Rezende Pinto *

\section{RESUMO}

Este artigo parte da hipótese de que, se a vinculação constitucional de uma parte da receita de impostos para a educação foi uma conquista fundamental no sentido de garantir um patamar minimo de recursos, ela não tem sido suficiente para assegurar o financiamento de um ensino com um padrão mínimo de qualidade, como determina a Constituição Federal e a Lei de Diretrizes e Bases da Educação Nacional. O trabalho chama a atenção para a urgência de se estabelecer o valor de custo aluno que assegure esse padrão mínimo de qualidade de ensino, apresenta uma simulação desse valor para um dado padrão de funcionamento de uma escola e avalia o impacto financeiro de sua adoção em toda a educação básica.

Palavras-chave: Financiamento da educação. Custo-aluno. Qualidade. Fundef. Fundeb.

* Doutor em Educação pela Universidade Estadual de Campinas (Unicamp, 1994). Professor da Faculdade de Filosofia, Ciências e Letras de Ribeirão Preto da Universidade de São Paulo - FFCLRP-USP (jmrpinto@ffclrp.usp.br). 
De forma sintética, podemos dividir a história do financiamento da educação no Brasil em três períodos. Uma primeira fase, que podemos chamar de "terceirizada", na qual o Estado delegou aos jesuítas o monopólio e o financiamento da educação básica (1749-1759). Um segundo período, no qual onde a responsabilidade principal ficou a cargo das câmaras municipais e dos governos estaduais através de dotações orçamentárias. Por fim, uma terceira etapa, iniciada com a Constituição Federal de 1934, que introduziu o princípio da vinculação de um percentual mínimo da receita de impostos dos três níveis de governo para o financiamento da educação. Esse princípio da vinculação constitucional de recursos para a educação, com exceção dos períodos ditatoriais (Constituições Federais de 1937 e de 1967), tem sido praticamente o único meio de se assegurar recursos públicos para a manutenção e o desenvolvimento do ensino (MELCHIOR, 1997, ALMEIDA, 1989, PINTO, 2000 e SENA, 2002). Atualmente o percentual mínimo da receita de impostos (considerando-se as transferências de um nível de governo para o outro) que deve ser destinado à manutenção e desenvolvimento do ensino é de $18 \%$ para a União, e de $25 \%$ para Estados e Municípios. Quando as constituições estaduais ou as leis orgânicas municipais fixarem um percentual mínimo superior a esse, passa a valer este novo índice. Em São Paulo, por exemplo, ele é de 30\%, e no Rio Grande do Sul e no Rio de Janeiro, o percentual mínimo é de 35\% da receita de impostos para a manutenção e desenvolvimento do ensino.

O principal problema dessa sistemática de vinculação de recursos é que, se ela representou um avanço frente à situação anterior, os valores financeiros efetivamente propiciados por aluno ainda são muito baixos. Assim é que, segundo estudo feito pelo Inep (ALMEIDA, 2001), o gasto médio por aluno no ensino fundamental no Brasil, em 1999 , foi de $\mathrm{R} \$ 691$, o que representaria uma "mensalidade" $\mathrm{R} \$ 58$, um valor claramente inferior aos cobrados por qualquer instituição privada e insuficiente para se assegurar um mínimo de qualidade.

O corolário natural dos baixos valores gastos por aluno são os baixos salários dos professores, já que esse é o principal componente no custo/manutenção de um aluno. Assim, segundo ainda levantamento do Inep feito com base nos dados da PNAD do IBGE (SAMPAIO et al., 2002), em 2001, o salário médio mensal de um professor que atuava no ensino fundamental era de $\mathrm{R} \$ 462$ para os que lecionavam de $1^{\mathrm{a}}$ a $4^{\mathrm{a}}$ série e de R \$ 600 para aqueles que lecionavam de $5^{\mathrm{a}}$ a $8^{\mathrm{a}}$ série; isto, incluindo todas as suas jornadas. Cabe comentar que todos esses dados já se referem a anos posteriores à implantação do Fundef (Fundo de Manutenção e Desenvolvimento do Ensino Fundamental e de Valorização do Magistério), o que mostra seu pequeno impacto, tanto na melhoria salarial quanto nos valores gastos por aluno.

Um dado novo e positivo neste quadro de tantas preocupações foi a introdução, através da Emenda Constitucional no 14 de 12.09.1996, a mesma que criou o Fundef, de um novo postulado no financiamento da educação determinando que, além da vinculação de um percentual mínimo de recursos para a manutenção e desenvolvimento do ensino, a União deverá exercer uma função redistributiva supletiva, de forma a garantir eqüalização de oportunidades educacionais e padrão minimo de qualidade de ensino, mediante assistência técnica e financeira aos Estados, ao Distrito Federal e aos Municípios (CF, art. $211, \$ 1^{\circ}$ ), princípio que é também abraçado pela LDB (Lei 9.394/96) em seu art. 74, 
que determina que esse custo mínimo por aluno que deve assegurar um ensino de qualidade será calculado pela União, ao final de cada ano, considerando variações regionais no custo dos insumos e as diversas modalidades de ensino. Por enquanto, essa sistemática só tem sido utilizada no ensino fundamental em virtude do Fundef, e o critério básico utilizado pela União, em desrespeito flagrante à Lei 9.424/96, que regulamenta esse fundo, não tem sido a busca de um ensino de qualidade, mas o quanto o Ministério da Fazenda entende como um valor aceitável para não comprometer a redução do déficit público (MONLEVADE; FERREIRA, 1997 e PINTO, 1999). Para se ter uma idéia do impacto do não-cumprimento, por parte da União, da fórmula do valor mínimo a ser gasto por aluno constante na Lei 9.424/96, basta dizer que o ensino fundamental público deixou de receber, desde 1998, mais de R $\$ 20$ bilhôes, que seria a cota devida pelo governo federal.

Portanto, pela nova sistemática definida pela Constituição Federal e pela LDB (Lei 9.394/96), além da aplicação dos percentuais mínimos em ensino, o que não tem ocorrido de forma fácil, os poderes públicos devem assegurar um mínimo de insumos por aluno que assegure um ensino de qualidade, e cabe à União garantir que esse valor seja oferecido de forma equiânime para todos os estudantes brasileiros, independentemente de morarem numa região rica ou pobre, ou de freqüentarem uma escola municipal, ou estadual. Existem, assim, duas tarefas a serem cumpridas, visando atender ao ordenamento legal por parte dos administradores públicos e pelos pesquisadores da área. Em primeiro lugar, é necessário desenvolvermos estudos que apontem para um valor adequado de custoaluno que assegure um ensino de qualidade, tendo em vista, é claro, as condições econômicas do País. Se esse valor não pode ser os US\$ 6.200/aluno-ano dos EUA, com certeza também não são admissíveis os $\mathrm{R} \$ 443,60$ /aluno-ano, que foi o valor propiciado pelo Fundef, em 2003 (já com o "complemento" da União), no Estado do Maranhão.

O Brasil é reconhecidamente carente de estudos na área de custos educacionais, contudo alguns trabalhos que tratam sobre o tema apontam que os sistemas de ensino que oferecem um padrão de qualidade razoável gastam entre $20 \%$ e $30 \%$ do PIB per capita por aluno (entre $\mathrm{R} \$ 1.740$ e $\mathrm{R} \$ 2.600$, considerando o PIB per capita de 2003) (PARO, 1985, LUCE; FARENZENA, 1998 e PINTO, 1999). O próprio governo federal permite uma dedução no Imposto de Renda da Pessoa Física, devido a gastos educacionais, de cerca de $\mathrm{R} \$ 2.000$ por pessoa, valor que correspondia a $23 \%$ do PIB per capita de 2003. O segundo campo que merece estudo é o que trata das diferenças entre os gastos por aluno nas diversas regiões do país e nos diferentes sistemas. ${ }^{1}$ Aqui também a situação é preocupante; segundo os dados publicados pelo Inep (ALMEIDA, 2001), em 1999, o gasto médio por aluno no ensino fundamental variou de $\mathrm{R} \$$ 435/aluno-ano no Maranhão até R\$ 1.475/aluno-ano, valor praticado pelo DF. Isso representa uma diferença de 3,4 vezes. A discrepância aparece também quando analisamos, para um mesmo Estado e mesmo nível de ensino, as diferenças nos gastos por aluno entre as diferentes redes. Assim é que, em 1999, no Espírito Santo, os gastos por aluno no ensino fundamental da rede municipal foram 2,5 vezes maiores do que aqueles praticados pela rede estadual. Se é inegável que o Fundef contribuiu para reduzir essas diferenças absurdas entre dependências administrativas de um mesmo Estado que acabam gerando o "aluno estadual" e o "aluno municipal" com direitos distintos, esse fundo pouco fez para reduzir as diferenças entre os Estados da Federação. Assim é que, em 2003, o maior valor por aluno 
(Roraima, com R\$ 1.601,90/aluno) foi 3,6 vezes o menor valor (Maranhão, com R\$ 443,60/aluno), para um valor médio de R \$ 787/aluno-ano. O Gráfico 1, tendo por base os valores por aluno do Fundef para o ano de 2003, mostra o quão grande ainda é o efeito das disparidades regionais. Pelo gráfico, constata-se que em oito Estados da Federação (MA, PI, BA, PA, CE, AL, PE e PB), em 2003, o Fundef propiciou, em média, menos que $\mathrm{R} \$ 45 /$ mês por aluno. Pelo Gráfico constata-se também que se fosse cumprido pela União o $\$ 1^{\circ}$ do art. $6^{\circ}$ da Lei $9.424 / 96$, o valor mínimo em 2003 não poderia ser inferior a $\mathrm{R} \$ 787 /$ aluno-ano (valor médio) e as discrepâncias entre Estados se reduziriam de forma significativa. Cumprida a lei pelo governo federal, em 200313 estados estariam recebendo complemento da União (MA, PI, BA, PA, CE, AL, PE, PB, AM, RN, MG, GO e SE) e o governo federal teria aplicado no fundo cerca de R 44 bilhões, o que corresponderia, ainda assim, a menos de $14 \%$ dos recursos do fundo. Como se furtou a cumpri-la, a Uniāo contribuiu com apenas cerca de 3\% dos recursos do fundo, recebendo complementação apenas os Estados da Bahia, Maranhão, Pará e Piauí.

\section{Gráfico I - R\$ por aluno propiciado pelo FUNDEF por UF - 2003}

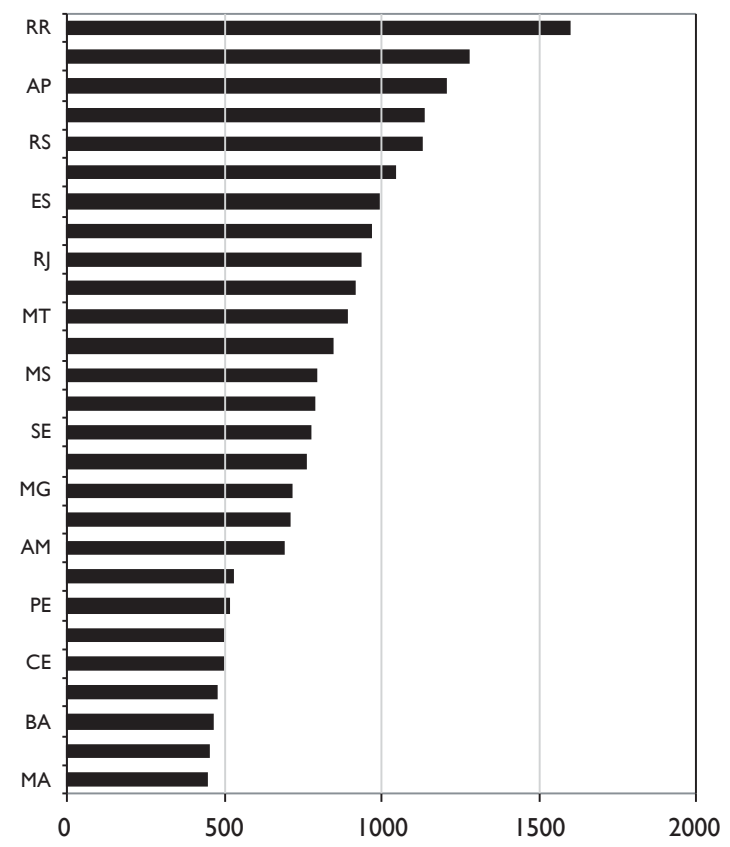

Fonte: Dados obtidos em Boletim do Fundef, Dezembro de 2003 (www.stn.fazenda.gov.br) 
Desta forma, é fundamental dotar o País de um sistema de financiamento que assegure um ensino de qualidade, assim como de mecanismos de transferência de recursos entre os níveis de governo que busquem evitar essas disparidades observadas em nosso sistema.

Aproveitando a experiência do Fundef, que mostrou que a criação de fundos estaduais não é suficiente, por si só, para reduzir as discrepâncias nos gastos por aluno entre os diferentes Estados e que mostrou também que a definição do que seja o valor mínimo gasto por aluno não pode ficar nas mãos executivo federal (ARELARO, 1999 e PINTO, 1999), entendemos que é necessário iniciar, no Brasil, o esforço de explicitação de quais são os insumos mínimos necessários para a construção de uma escola de qualidade, conforme requer a legislação. Tendo em mente essa meta, apresentamos a seguir uma estimativa inicial de custo de uma escola que, entendemos, preenche critérios básicos de qualidade. Trata-se de uma proposta inicial com o objetivo de, tão-somente, fomentar a discussão entre os educadores.

Assim, construímos uma escola hipotética de Ensino Fundamental de $1^{\text {a }}$ a $4^{\mathrm{a}}$ série, na qual os alunos teriam uma jornada semanal de 30 horas, e os professores de 40 horas (com 10 horas para atividades extra-classe de planejamento e avaliação a serem cumpridas na escola). ${ }^{2}$ Seria uma escola com 500 alunos e uma média de 25 alunos por turma. A escola contaria com um diretor, um coordenador pedagógico, cinco estagiários remunerados, um bibliotecário, além de seis funcionários de apoio administrativo e operacional. Os valores são apresentados na Tabela 1, inclusive com os salários estimados. $\mathrm{Ou}$ seja, estamos já sinalizando, em sintonia com a LDB, para uma escola de jornada única (6 horas/dia) e um professor de dedicação exclusiva. Cabe ainda comentar que é fundamental que se vincule o custo-aluno padrão mínimo de qualidade, que é o que propomos nesta tabela, com o salário mínimo profissional a ser pago aos professores. O modelo proposto, cujo salário médio seria de $\mathrm{R} \$ 1.200,00 /$ mês, permite a fixação de um Piso Salarial Nacional de R \$ 800,00/mês, considerando as diretrizes para a carreira dos profissionais do magistério definidas pela CNE (Conselho Nacional de Educação).

Tabela 2 - Proposta de Custo/aluno-ano que assegure um Padrão Mínimo de Qualidade (CAPMQ) de uma escola de Ensino Fundamental de $I^{\mathrm{a}}$ a $4^{\mathrm{a}}$ Série (ano base: 2003)

\begin{tabular}{|c|c|c|c|c|c|}
\hline $\begin{array}{c}\text { Custos em } \\
\text { sala de } \\
\text { aula }\end{array}$ & No & $\begin{array}{c}\text { Custo } \\
\text { unitário } \\
\mathbf{R} \$\end{array}$ & $\begin{array}{c}\text { Custo } \\
\text { total/ano } \\
\mathbf{R} \$\end{array}$ & $\begin{array}{c}\text { Custo } \\
\text { aluno/ano } \\
\mathbf{R} \$\end{array}$ & \% do total \\
\hline Professores & 20 & 1200 & 319920 & 640 & $54,4 \%$ \\
\hline $\begin{array}{c}\text { Material } \\
\text { didático }\end{array}$ & 500 & 30 & 15000 & 30 & $2,6 \%$ \\
\hline Equipamento & & & 10000 & 20 & $1,7 \%$ \\
\hline Sub-total & & & $\mathbf{3 4 4 9 2 0}$ & $\mathbf{6 9 0}$ & $\mathbf{5 8 , 6 \%}$ \\
\hline
\end{tabular}


Tabela 2 - Continuação

\begin{tabular}{|c|c|c|c|c|c|}
\hline $\begin{array}{c}\text { Custos no } \\
\text { âmbito da } \\
\text { escola }\end{array}$ & $\mathbf{N}^{\circ}$ & $\begin{array}{c}\text { custo } \\
\text { unitário } \\
\text { R\$ }\end{array}$ & $\begin{array}{c}\text { Custo } \\
\text { total/ano } \\
\text { R\$ }\end{array}$ & $\begin{array}{c}\text { Custo } \\
\text { aluno/ano } \\
\text { R\$ }\end{array}$ & $\%$ do total \\
\hline \multicolumn{6}{|c|}{ Administração geral } \\
\hline Direção & 1 & 1500 & 19995 & 40 & $3,4 \%$ \\
\hline Secretaria & 1 & 500 & 6665 & 13 & $1,1 \%$ \\
\hline $\begin{array}{l}\text { Inspetor de } \\
\text { alunos }\end{array}$ & 2 & 300 & 7998 & 16 & $1,4 \%$ \\
\hline Serviços gerais & 3 & 300 & 11997 & 24 & $2,0 \%$ \\
\hline Sub-total & & & 46655 & 93 & $7,9 \%$ \\
\hline \multicolumn{6}{|c|}{ Suporte Pedagógico } \\
\hline $\begin{array}{c}\text { Coord. } \\
\text { pedagógico }\end{array}$ & 1 & 1200 & 15996 & 32 & $2,7 \%$ \\
\hline Estagiários & 5 & 240 & 14400 & 29 & $2,4 \%$ \\
\hline Bibliotecário & 1 & 1200 & 15996 & 32 & $2,7 \%$ \\
\hline Sub-total & & & 46392 & 93 & $7,9 \%$ \\
\hline \multicolumn{6}{|c|}{ Operação e manutenção } \\
\hline Água/luz/fone & 12 & 1800 & 21600 & 43 & $3,7 \%$ \\
\hline $\begin{array}{l}\text { Material de } \\
\text { limpeza }\end{array}$ & 12 & 300 & 3600 & 7 & $0,6 \%$ \\
\hline $\begin{array}{l}\text { Material de } \\
\text { escritório }\end{array}$ & 12 & 500 & 6000 & 12 & $1,0 \%$ \\
\hline $\begin{array}{c}\text { Conservação } \\
\text { predial }\end{array}$ & 12 & 500 & 6000 & 12 & $1,0 \%$ \\
\hline Manut. Equipam. & 12 & 300 & 3600 & 7 & $0,6 \%$ \\
\hline Sub-total & & & 40800 & 82 & $6,9 \%$ \\
\hline \multicolumn{6}{|c|}{ Alimentação } \\
\hline Merendeiras & 3 & 400 & 15996 & 32 & $2,7 \%$ \\
\hline $\begin{array}{c}\text { Alimentos } \\
\text { (2 refeições/dia) }\end{array}$ & 1000 & 0,3 & 60000 & 120 & $10,2 \%$ \\
\hline Sub-total & & & 75996 & 152 & $12,9 \%$ \\
\hline \multicolumn{6}{|c|}{ Custos na administração central } \\
\hline $\begin{array}{l}\text { Formação } \\
\text { profissional }\end{array}$ & 20 & 200 & 4000 & 8 & $0,7 \%$ \\
\hline $\begin{array}{c}\text { Administração e } \\
\text { Superv. }\end{array}$ & \multicolumn{2}{|c|}{$5 \%$ do custo total } & 29409 & 59 & $5,0 \%$ \\
\hline Sub-total & & & 33409 & 67 & $5,7 \%$ \\
\hline Total Geral & & & R\$ 588.172 & R\$ 1.176 & $100,0 \%$ \\
\hline
\end{tabular}

Fonte: Tabela elaborada pelo autor.

Obs.: Considerou-se apenas o custo de manutenção e de pequenos investimentos, não estando incluídos os custos de construção, já que estes ocorrem apenas uma vez. 
Como vimos, o modelo proposto chegou a um valor de custo por aluno de $\mathrm{R} \$ 1.176$ / ano, que chamaremos de CAPMQ (Custo Aluno Padrão Mínimo de Qualidade), incluindo-se os gastos com alimentação escolar. Qual seria o impacto financeiro da generalização desse padrão de financiamento estabelecendo esse valor como o patamar mínimo de custo/ aluno-ano do País? Para chegar a esse valor, inicialmente consideraremos os seguintes diferenciais em relação ao custo de $1^{\mathrm{a}}$ a $4^{\mathrm{a}}$ série (CAPMQ) fixado: Creche, 1,5 vezes o CAPMQ; Pré-escola, 1,3 vezes; 5a a 8 a do Ensino Fundamental e Ensino Médio, 1,05 vezes; Educação Especial, 1,3 vezes, e a Educação de Jovens e Adultos terá o mesmo custoaluno do ensino regular, considerando o respectivo nível de ensino. Feitas essas considerações e tomando o total de alunos de 2003 , chegaremos à cifra de aproximadamente $\mathrm{R} \$$ 62,6 bilhōes, para garantir esse patamar de CAPMQ, um valor que corresponde a $4 \%$ do PIB do referido ano. Um dado interessante: este é o percentual do PIB que os países desenvolvidos geralmente destinam à educação básica. Se imaginarmos um Fundeb onde Estados e Municípios contribuam com 25\% de sua receita líquida de impostos, a contribuição da União para viabilizar esse CAPMQ seria de cerca de $1 \%$ do PIB, um valor que, embora elevado, é plenamente factível para um governo federal que tem em suas mãos uma receita (deduzidas as transferências constitucionais) de cerca de $20 \%$ do PIB, considerando impostos e contribuições.

Essas simulações feitas mostram que, se houver uma iniciativa mais firme por parte do governo federal, é plenamente possível o País dar um salto de qualidade no padrão da educação básica atualmente oferecida. Contudo, tendo em vista as metas quantitativas e qualitativas definidas pelo Plano Nacional de Educação (Lei 10.172/2001), não basta melhorar o padrão de qualidade do ensino oferecido aos alunos que se encontram atualmente matriculados nas escolas do País; temos grandes desafios de expansão com qualidade da educação infantil, do ensino médio e da educação superior. Estudos feitos por ocasião da elaboração da proposta de Plano Nacional de Educação da Sociedade Brasileira (CONED, 1997), corroborados por levantamento feito por Grupo de Trabalho criado pelo MEC (INEP, 2001), apontam que, para atender as metas fixadas pelo PNE, o Brasil deveria gastar, durante um período de seis a oito anos, entre $8 \%$ e $10 \%$ de seu PIB em educação.

Tendo em vista que o potencial de recursos atualmente propiciado pela vinculação constitucional de impostos para a manutenção e desenvolvimento do ensino é da ordem de 4,3\% do PIB, surge, então, inevitavelmente, a pergunta: qual a fonte provável desses recursos adicionais? Um dos mecanismos de efeito imediato e que não implicam em aumento da carga tributária seria a aprovação de uma emenda constitucional que determinasse, por exemplo, que a vinculação para o ensino incidisse não apenas sobre a receita de impostos, mas que englobasse também as contribuiçóes sociais e econômicas que, em 2003, representavam, só na esfera federal, o equivalente a 15\% do PIB, dos quais apenas $0,2 \%$ do PIB (que corresponde ao salário-educação) beneficia a educação. Uma medida dessa natureza, que teria pouco impacto sobre as finanças dos Estados e Municípios, representaria um acréscimo de recursos para a educação da ordem de 2,7\% do PIB. Há também os recursos da DRU (Desvinculação das Receitas da União); a retirada de seus efeitos sobre a educação propiciaria mais $\mathrm{R} \$ 4,1$ bilhões, tendo por base o ano de 2003 . Além desses recursos, nunca é demais ressaltar aqueles que adviriam da melhoria da eficácia do sistema arrecadador (segundo o ex-Secretário da Receita Federal, Everardo Maciel, tendo 
por base os dados da CPMF, o equivalente a um PIB escapa à tributação no País) e da rediscussão das isenções e incentivos fiscais, que somam cerca de $2 \%$ do PIB, só na esfera federal. Uma medida heterodoxa a ser considerada também é o uso do déficit público para financiar a educação, tendo em vista a relação que existe entre investimentos educacionais públicos e desenvolvimento econômico, o que não significa, ao contrário do que diz a Teoria do Capital Humano, uma relação direta entre aumento de escolaridade e melhoria de renda da população. Considerando que foi o déficit que financiou boa parte das "políticas de desenvolvimento" das últimas décadas, as quais, como mostra o trabalho de Barros, Henriques e Mendonça (2000), não alteram em nada a constrangedora distribuição de renda do País, por que não o utilizar para fazer uma revolução educacional no País? Esses autores mostram que, de 1978 a 1998, com irritante regularidade, enquanto o $1 \%$ mais rico ficou com cerca de $12 \%$ da renda nacional, os $40 \%$ mais pobres ficaram com cerca de $9 \%$ da mesma. Considerando a razão entre a renda dos $20 \%$ mais ricos e aquela dos $20 \%$ mais pobres, e tendo por base dados das Nações Unidas, esses autores mostram que nos classificamos em último lugar em um conjunto de 50 países. Mostram ainda que, enquanto no Brasil o número de pessoas vivendo abaixo da linha de pobreza, em 1998, era de 33\%, em países com renda per capita equivalente esse índice, situava-se em torno de $10 \%$.

Por isso, nunca é demais lembrar que políticas de distribuição de renda representam a melhor de reforma tributária que o país pode sonhar. Programas de redução da pobreza de curto prazo, como o bolsa-escola e equivalentes, e de médio prazo, como a reforma agrária, a ampliação da oferta e da qualidade da escola e do acesso ao crédito, possuem um impacto forte e imediato na receita pública. Isto acontece porque a carga fiscal no Brasil, ao contrário do que ocorre em países com distribuição de renda mais justa, é majoritariamente composta de tributos sobre o consumo. Nos segmentos mais pobres, todo aumento de renda transforma-se em consumo, e, consequentemente, em mais receita de impostos, ao contrário do que ocorre com as faixas mais abastadas, que, ou poupam, ou vão gastar no exterior, lá gerando empregos e tributos.

Concluindo, gostaríamos de ressaltar que, se a vinculação constitucional de recursos para o ensino constituiu-se em uma etapa fundamental para se assegurar o financiamento da educação no Brasil, ela não é suficiente para propiciar valores financeiros que assegurem um ensino com um padrão mínimo de qualidade para todos, como determina a mesma Constituição Federal e a LDB. Tendo consciência disto, o próprio legislador constituinte definiu os índices percentuais ali estabelecidos como percentuais mínimos a serem aplicados no ensino. Portanto, a grande tarefa que temos pela frente é, uma vez fixados, em quantidade e qualidade, os insumos necessários para uma escola cidadã, e aferidos os seus custos, assegurar a destinação desses recursos nos orçamentos dos diferentes níveis de governo, independentemente do percentual da receita de impostos que eles representem. Assim trabalham os países desenvolvidos e assim age o governo brasileiro, por exemplo, para manter sua política monetária. Basta dizer que, mesmo sem possuir qualquer vinculação constitucional específica, foram gastos, em média, 8,7\% do PIB com encargos financeiros da União. 


\section{Notas}

1. Em 2003 o Inep financiou um estudo levado a efeito por grupos de 10 universidades do País com o objetivo de levantar o custo-aluno de 100 escolas de diferentes níveis e localizaçóes que apresentavam condiçōes de oferta adequadas para um ensino de qualidade. Os resultados devem ser divulgados este ano.

2. Para se ter uma idéia dessa metodologia, pode-se visitar o sitio do Inep (www.inep.gov.br) e lá procurar por "Simulador de custo-aluno".

\section{Referências}

ALMEIDA, Ivan Castro de. Gastos com educação no período de 1994 a 1999. Revista Brasileira de Estudos Pedagógicos, Brasília, v. 82, n. 200/201/202, p. 137-198, jan./dez. 2001 (publicada em 2003).

ALMEIDA, José Ricardo Pires de. História da instrução pública no Brasil, 1500 a 1889. São Paulo: Educ; Brasília: Inep - MEC, 1989 (edição original de 1889, em francês).

ARELARO, Lisete Regina Gomes. Financiamento e qualidade da educação brasileira. Algumas reflexōes sobre o documento "Balanço do primeiro ano do Fundef - Relatório MEC". In: DOURADO, Luiz Fernandes (Org.). Financiamento da educação básica. Campinas: Autores Associados e Goiânia: Edufg, 1999. p. 27-46.

BARROS, Ricardo Paes de; HENRIQUES, Ricardo; MENDONÇA, Rosane. Evolução recente da pobreza e da desigualdade: marcos preliminares para a política social no Brasil. In: Pobreza e política social, Cadernos Adenauer, n. 1. São Paulo: Fundação Konrad Adenauer, 2000.

BRASIL. Emenda Constitucional n. 14/96 e Leis n. 9.394/96, n. 9.424/96, n. 9.473/97. Brasília: Congresso Nacional.

BRASIL. Leis n. 9.394/96, n. 9.424/96. Brasília: Congresso Nacional.

BRASIL. Constituição da República Federativa do Brasil. São Paulo: Saraiva.

CONED. Plano Nacional de Educação. Proposta do II CONED. Belo Horizonte. 1997.

INEP. Relatório do Grupo de Trabalho sobre Financiamento da Educação. Revista Brasileira de Estudos Pedagógicos, Brasília, v. 82, n. 200/201/202, p. 117-136, jan./dez. 2001 (publicada em 2003).

LUCE, Maria Beatriz; FARENZENA, Nalú. Financiamento da educação infantil e do ensino fundamental nos municípios do Rio Grande do Sul: estudos das fontes e usos de recursos e custos educacionais. Porto Alegre: UFRGS, Faced, PPGEDU, Núcleo de Estudos de Política e Gestão da Educação, 1998. 154 p.

MELCHIOR, José Carlos de Araújo. Mudanças no financiamento da educação no Brasil. Campinas: Autores Associados, 1997.

MONLEVADE, João; FERREIRA, Eduardo Beurmann. Educação pública no Brasil: contos \& de\$conto\$. Ceilândia - DF: Idéa, 1997.

PARO, Vitor Henrique. (1985) ?????

PINTO, José Marcelino de Rezende. Os recursos para a educação no Brasil no contexto das finanças públicas. Brasília: Plano, 2000.

. Um fundinho chamado fundão. In: DOURADO, Luiz Fernandes (Org.). Financiamento da educação básica. Campinas: Autores Associados e Goiânia: Edufg, 1999. p. 85-98.

SAMPAIO, Carlos Eduardo Moreno et al. Estatísticas dos professores no Brasil. Revista Brasileira de Estudos Pedagógicos, Brasília, v. 83, n. 203/204/205, p. 85-120, jan./dez. 2002 (publicada em 2003).

SENA, Paulo. A União e a aplicação dos recursos vinculados à manutenção e ao desenvolvimento do ensino. Revista Brasileira de Estudos Pedagógicos, Brasília, v. 83, n. 203/204/205, p. 7-22, jan./dez. 2002 (publicado em 2003). 


\title{
Financing of education in Brazil: from the constitutional binding to the construction of a school of minimum quality standards
}

\section{Abstract}

This article starts on the hypothesis that, while the constitutional binding of part of the income of taxes for education has been a fundamental conquest in the sense of guaranteeing a minimum level of resources, it has not been sufficient to ensure the financing of an education with a minimum standard of quality as determined by the Federal Constitution and the Law of Directives and Bases for National Education. This analysis points out to the urgency of establishing the value of student costs which guarantees this minimum standard of quality of education. It presents a simulation of this value for a given standard of functioning of a school and evaluates the financial impact of its adoption in all of the basic education system.

Keywords: Financing of education. Student cost. Quality. Fundef. Fundeb.

\section{Le financement de l'éducation au Brésil : de l'exigence constitutionnelle à la construction d'une école avec des niveaux minimes de qualité}

Résumé

Cet article part de l'hypothèse que, si l'exigence constitutionnelle qu'une partie de la recette des impôts pour l'éducation fut une conquête fondamentale dans le sens de garantir un niveau minime de ressources, elle n'a pas été sufisante pour assurer le financement d'un enseignement avec un niveau minimum de qualité comme le détermine la Constitution Fédérale et la Loi de Directrices et Bases de l'Éducation Nationale. Ce travail attire l'attention sur l'urgence que soit établit une valeur du coût élève qui garantisse ce niveau minimum de qualité de l'enseignement. Il présente en plus une simulation de cette valeur pour un niveau donné de fonctionnement d'une école et évalue l'impacte financier de son adoption pour tout l'enseignement de base.

Mots clefs : Financement de l'enseignement. Cô̂t élève. Qualité. Fundef. Fundeb.

\section{Financiación de la educación en Brasil: de la vinculación constitucional a la construcción de una escuela con patrones mínimos de cualidad}

\section{Resumen}

Este artículo parte de la hipótesis de que si la vinculación constitucional de una parte de la recaudación de los impuestos para la educación fue una conquista fundamental en el sentido de garantizar un nivel mínimo de recursos, ella no ha sido suficiente para garantizar el financiación de la enseñanza con un patrón mínimo de cualidad como lo determina la constitución federal y la ley de directrices y bases de la educación nacional. El trabajo llama la atención para la urgencia de que se establesca el valor de costo alumno que asegure ese patrón mínimo de cualidad de la enseñanza y presenta una simulación de ese valor para un dado patrón de funcionamento de una escuela y evalúa el impacto financiero de su adopción en toda la educación básica.

Palabras-clave: Financiación de la educación. Costo alumno. Cualidad. Fundef. Fundeb.

\author{
Recebido: 21.01 .2005
}

Aceito: 15.04.2005 